(2) Open Access Full Text Article

\title{
Synthesis and characterization of multi- allyl-functionalized polylactic acid and polyhydroxybutyrate polyurethane, and their cross-linking by copolymerization with 2-hydroxylethyl methacrylate
}

This article was published in the following Dove Press journal:

Reports in Organic Chemistry

20 July 2015

Number of times this article has been viewed

\author{
Hang Shen ${ }^{1-3}$ \\ Caroline Pillon ${ }^{1-3}$ \\ Jianding Chen ${ }^{4}$ \\ Mohamed Tahal-3 \\ 'Université de Lyon, ${ }^{2}$ CNRS, UMR, \\ Ingénierie des Matériaux Polymères, \\ ${ }^{3}$ Université de Saint-Etienne, Jean \\ Monnet, Saint-Etienne, France; \\ ${ }^{4}$ Laboratory of Advanced Materials \\ Processing, East China University of \\ Science and Technology, Shanghai, \\ People's Republic of China
}

\begin{abstract}
Molar mass-controlled dihydroxyl telechelic polylactide and polyhydroxybutyrate oligomers were synthesized by ring-opening polymerization or transesterification. These oligomers were used as soft segments in two-step allyl-functionalized poly(ester-urethane) syntheses. The expected structures were confirmed by ${ }^{1} \mathrm{H}$ nuclear magnetic resonance spectroscopy, size exclusion chromatography, and differential scanning calorimetric, and the obtained polyurethanes were copolymerized with 2-hydroxylethyl methacrylate. Thermal degradations of the dihydroxyl telechelic oligomers, double-bond functionalized poly(ester-urethane)s, and the issued networks were analyzed using thermogravimetry coupled by Fourier transform infrared spectroscopy analysis.
\end{abstract}

Keywords: photocurable, polylactide, polyhydroxybutyrate, poly(ester-urethane), structure design, network, thermal degradation

\section{Introduction}

Biodegradable polyurethanes (PUs) have been widely used in biomedical fields, ${ }^{1}$ such as in blood-contact applications, contact lenses, surgical implants, and separation membranes, ${ }^{2-4}$ because of their good physicochemical and mechanical properties while exhibiting acceptable biological performances. In recent years, these materials have also been extensively studied and used in new applications, such as thermo-responsive materials ${ }^{5}$ and shape-memory materials ${ }^{6}$ because of their contribution in the reduction of environmental issues inherent to nonbiodegradable materials.

These PUs are often synthesized by reaction of a diisocyanate with a mixture of hydrolytically unstable polyester oligomer, suitable to obtain multiphase materials having well-defined properties. ${ }^{5,7,8}$ The urethanes constitute the hard segments offering rigid character to the $\mathrm{PU}$, while the polyester oligomer part enlarges the molar mass and softens the polymer chains. Among the hydrolytically unstable polyester oligomers, and despite its inevitable drawbacks such as mechanical brittleness, low heat resistance, and synthesis costs, polylactic acid (PLA) plays a significant role as a constituent of biodegradable PUs for orthopedic implants as bio-resourced renewable polymers. ${ }^{9}$ Several studies concerning PLA-based PUs were reported in the literature. ${ }^{10-12}$ Naturally synthesized by microorganisms, polyhydroxybutyrate (PHB) has drawn increasing attention during the last decades for its biocompatibility coupled
Correspondence: Mohamed Taha FST, imp@ujm, Rue Dr Michelon, 42023 St-Etienne, Cedex, France Tel +3347748 I5 57

Email mohamed.taha@univ-st-etienne.fr 
with biodegradability. ${ }^{5,13}$ Even though the biomedical applications of PHB have been investigated for many years, ${ }^{14}$ the overall results seemed insufficient for practical applications due to its brittleness and a narrow thermo-processing window. Recently, hydroxyl telechelic PHB oligomers were obtained by transesterification. ${ }^{14,15}$ The use of those as biomaterials, such as blood-contact implant materials, was reported by Brzeska et $\mathrm{al}^{16}$ and Liu et al. ${ }^{17}$

In addition to the intrinsic properties of poly(esterurethane)s, their functionalization can broaden their scope, ${ }^{1,18-22}$ and the functionality of these PUs can also be altered by designing their structure, which also affects the mechanical properties of the PUs. ${ }^{23}$ In this study, the synthesis of poly(ester-urethane) s containing PLA or PHB segments and end-functionalization with double bonds is performed through simple steps. These poly(ester-urethane)s with controlled branched structures and functionalities are used to prepare cross-linked materials having variable properties by copolymerization with 2-hydroxyethyl methacrylate (HEMA).

\section{Experimental section}

\section{Materials}

PHB PHI002 ${ }^{\mathrm{TM}}$ (number-average molecular weight $\left[M_{\mathrm{n}}\right]$ $=4,730 \mathrm{~g} \mathrm{~mol}^{-1},{ }^{1} \mathrm{H}$ NMR [nuclear magnetic resonance spectroscopy]) was purchased from NaturePLAST, Ifs, France. HEMA was purchased from Röhm GmbH, Sontheim/Brenz, Germany. 3,6-Dimethyl-1,4-dioxane-2,5-dione L-lactide (LLA), 4,4'-methylenebis(cyclohexyl isocyanate) ( $\left.\mathrm{H}_{12} \mathrm{MDI}\right)$, glycerol, 1,4-butanediol (BD), dibutyltin dilaurate (DBTDL), allylamine, tin(II) (2-ethylhexanoate) $\left(\mathrm{Sn}(\mathrm{Oct})_{2}\right)$ were purchased from Sigma-Aldrich (Lyon, France). Anhydrous dimethylformamide (DMF) and diethyl ether were purchased from Carlo Erba Reagents ${ }^{\mathrm{TM}}$, Rodano, MI, USA. The photo initiator was composed of the following reagents: $60 \mathrm{wt} \%$ of $\mathrm{CN} 381$ from Sartomer, West Chester, PA, USA (containing copolymerizable amine acrylate as synergist), $20 \mathrm{wt} \%$ of benzophenone from Aldrich, and $20 \mathrm{wt} \%$ of 2,2-diethoxyacetophenone from Aldrich. HEMA was distilled before use. Glycerol was dehydrated by $3 \AA$ molecular sieves (rod shape, size 1/16 inch, Fluka, Sigma-Aldrich) for 1 week before use. All other reagents were used as received without further purification.

\section{Synthesis of telechelic polylactide and polyhydroxybutyrate oligomers}

The synthesis of the dihydroxyl telechelic PLA oligomer was made as shown in Figure 1. Typically L-lactide was added into a $250 \mathrm{~mL}$ glass batch reactor designed for mixing viscous materials equipped with previously dried nitrogen flow and condenser, and heated at $130^{\circ} \mathrm{C}$ until all reagents were completely melted. Then a certain amount of BD, depending on the degree of polymerization $\left(\mathrm{Dp}_{\mathrm{n}}\right)$ of the synthesized oligomer and $\mathrm{Sn}\left(\mathrm{Oct}_{2}\right)$ (1\% of the LLA, mol/mol), was injected in. The copolymerization was kept under the previously dried nitrogen flow in a silica column for 3 hours. The synthesized oligomers were immediately characterized and used for the next step of the syntheses.

For the synthesis of dihydroxyl telechelic PHB, $10 \mathrm{~g}$ of PHB was dissolved in $100 \mathrm{~mL}$ of chloroform and refluxed for 45 minutes at $75^{\circ} \mathrm{C}$, until the system became homogeneous. Then $p$-toluenesulfonic acid (4.8 g) and BD (20 g) were injected in and mixed. The reaction was carried out at $75^{\circ} \mathrm{C}$ for 8-24 hours depending on the required molar mass of PHB. The obtained solution was washed thrice with distilled water, concentrated, and dried under vacuum at $70^{\circ} \mathrm{C}$ to remove the water. The obtained dihydroxyl telechelic $\mathrm{PHB}$ ranged from a brown liquid to a white solid at room temperature depending on its molar mass.

\section{Syntheses of polyurethane prepolymer and allyl-functionalized polyurethanes}

A typical synthesis procedure of PUs was as follows (Figure 2): glycerol and PLA (or PHB) oligomers were first introduced into a two-neck flask equipped with previously dried nitrogen flow and condenser. Anhydrous DMF was injected in as the solvent, and the system was magnetically stirred until it became homogeneous at room temperature. Then the $\mathrm{H}_{12} \mathrm{MDI}$

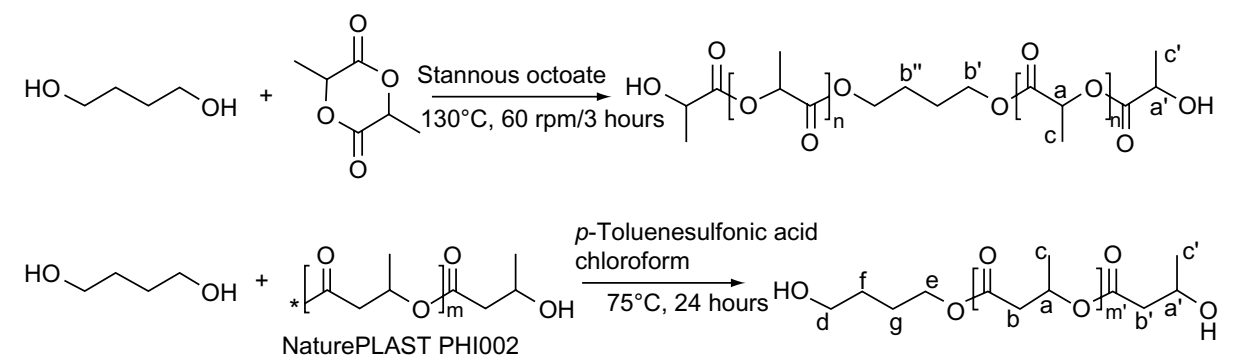

Figure I Synthesis of dihydroxyl telechelic polylactide and polyhydroxybutyrate. 


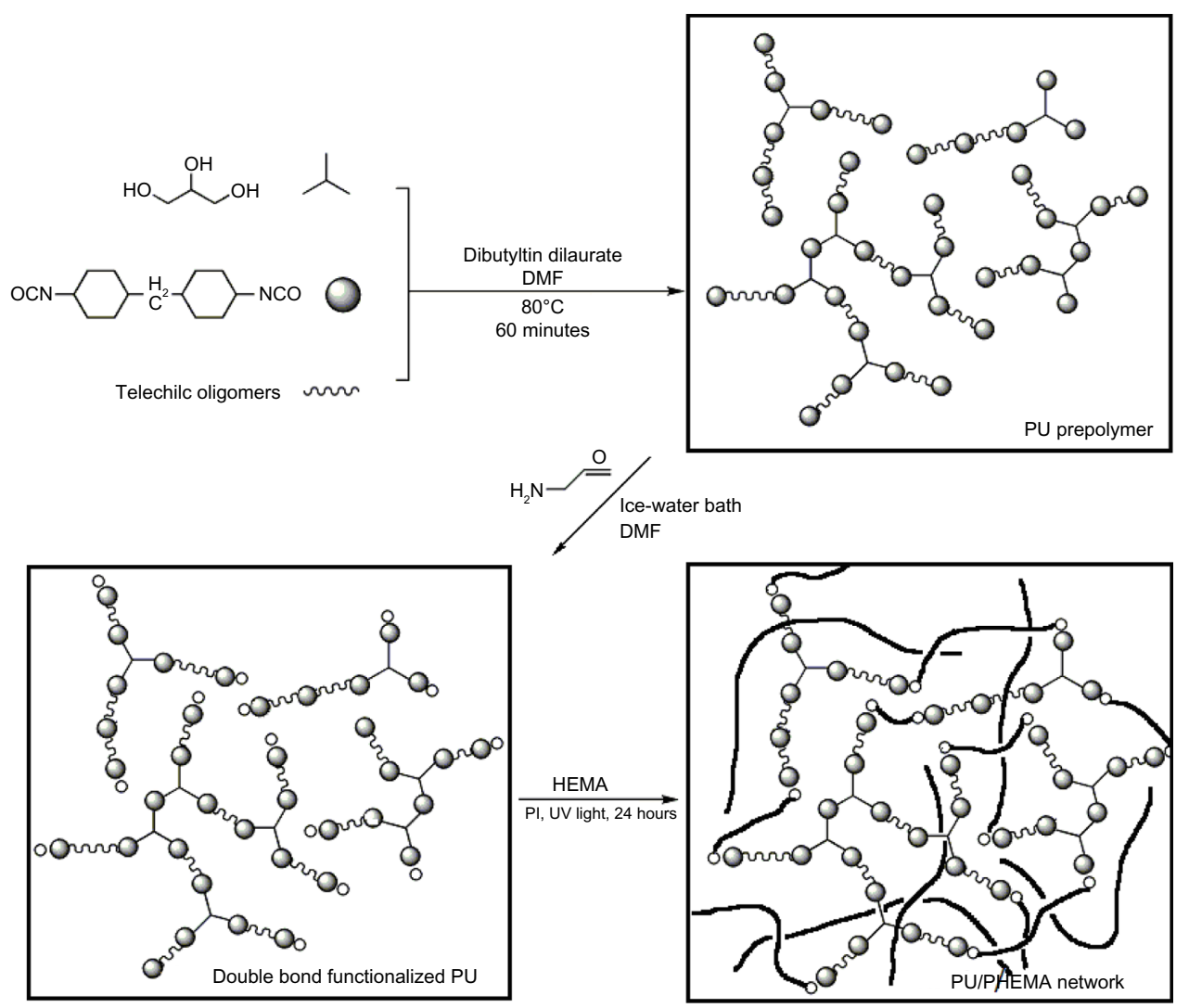

Figure 2 Two-step syntheses of PLA-/PHB-segmented, double-bond end-functionalized polyurethanes.

Abbreviations: DMF, dimethylformamide; PU, polyurethane; PHEMA, poly(hydroxyethyl methacrylate); HEMA, 2-hydroxyethyl methacrylate; PLA, polylactic acid; PHB; polyhydroxybutyrate; UV, ultra violet; PI, Photoinitiator.

was injected and mixed at room temperature for 5 minutes. Finally, the DBTDL was introduced as the catalyst and the whole system was stirred and kept at $80^{\circ} \mathrm{C}$ in an oil bath for 55 minutes. During the reaction, Fourier transform infrared (FTIR) spectroscopy was used to monitor the consumption of isocyanate groups.

The obtained PU solution was diluted with anhydrous DMF and placed in an ice-water bath with magnetic stirring. Then allylamine was added dropwise to react with the remaining isocyanate groups. The reaction was conducted until the remaining isocyanate groups completely reacted. Then, the products were precipitated in ethyl ether, redissolved in chloroform, and reprecipitated thrice in ethyl ether. Finally, the obtained solid was collected and dried under vacuum at room temperature for 24 hours and stored at $-20^{\circ} \mathrm{C}$.

\section{Methacrylated PU network formation by UV irradiation}

Different allyl-functionalized ( $\varepsilon$-polycaprolactone) PCLsegmented PUs were dissolved in HEMA with a mass ratio $M_{\mathrm{HEMA}}: M_{\mathrm{PU}}=1.5: 1$ at room temperature using a shaker until the solution became homogeneous. Then, the photo initiator was fully solubilized in the system by oscillation at room temperature for 3 minutes. An ultrasonic oscillator was used to remove bubbles before curing.

The mixtures were placed in low-density polyethylene molds $(100 \mathrm{~mm} \times 10 \mathrm{~mm} \times 100 \mu \mathrm{m})$ and cured in air with a fluorescent lamp, JAD STS-350, equipped with $8 \mathrm{~W} \times 3$ fluorescent tubes offering $\lambda=250 \mathrm{~nm}$ UV light. The mixtures were exposed at $3 \mathrm{~cm}$ for 24 hours. After curing, the samples were collected for analysis.

\section{Instrumentation}

FTIR absorption spectra were recorded on a Nicolet Nexus spectrometer (Thermo, Waltham, MA, USA; $400-4,000 \mathrm{~cm}^{-1}$ ) using attenuated total reflectance technique.

${ }^{1} \mathrm{H}$ NMR spectra were recorded in a $\mathrm{CDCl}_{3}$ solution at room temperature using a Bruker Avance II spectrometer (Bruker, Coventry, UK) operating at a frequency of $250 \mathrm{MHz}$. The chemical shift scales were calibrated on the basis of the tetramethylsilane (TMS) peak (0 ppm).

Differential scanning calorimetry (DSC) measurements for the allyl-functionalized PCL-segmented PUs and PU/ PHEMA networks were carried out with a Q10 calorimeter 
from TA Instruments (Guyancourt, France). Samples were transferred to hermetic pans, sealed, and analyzed from $-80^{\circ} \mathrm{C}$ to $210^{\circ} \mathrm{C}$ with a cooling/heating rate of $10^{\circ} \mathrm{C} \cdot \mathrm{min}^{-1}$. The glass transition temperatures were evaluated by identifying the inflection points from the data recorded during heating. Each sample underwent two rounds of heatingcooling cycles.

For the analysis of allyl-functionalized PLA-segmented PUs, size exclusion chromatography (SEC) was conducted using a system equipped with refractive index detector (Waters ${ }^{\circledR}$ 2414; Waters Corporation, Milford, MA, USA) and light scattering detector (Wyatt MiniDawnTreos; Wyatt Technology Corp, Santa Barbara, CA, USA). Two columns, HR 1 and HR 3, from Waters were used. The eluent was tetrahydrofuran $(\mathrm{THF})$, with a flow rate of $1 \mathrm{~mL} \cdot \mathrm{min}^{-1}$ and an elution temperature of $35^{\circ} \mathrm{C}$. The molar masses of the copolymers were determined using a calibration curve established on a set of polystyrene standards. For the analysis of allyl-functionalized PHB-segmented PUs, SEC was conducted using a system equipped with UV detector (Waters 486, wavelength $=280 \mathrm{~nm}$ ), light scattering detector $($ Wyatt TREOS), and refractive index detector (Shimadzu RID 10A; Shimadzu, Kyoto, Japan). Two columns PLgel $5 \mu \mathrm{m}$ MIXED-C and PLgel $20 \mathrm{~mm}$ Guard from Organic GPC (Agilent, Santa Clara, CA, USA) were used. The eluent was chloroform, with a flow rate of $1 \mathrm{~mL} \cdot \mathrm{min}^{-1}$ and an elution temperature of $22^{\circ} \mathrm{C}$. The samples tested were prepared with a concentration of $2 \mathrm{mg} \cdot \mathrm{mL}^{-1}$.

A thermogravimetric analyzer from Mettler Toledo (Columbus, OH, USA), TGA/DSC 1, was used to perform the thermogravimetric analysis (TGA). Thermal degradation experiments were done under nitrogen purge with a flow rate of $80 \mathrm{~mL} \cdot \mathrm{min}^{-1}$ for all experiments. Samples ranging from $15 \mathrm{mg}$ to $20 \mathrm{mg}$ were heated at a heating rate of $10^{\circ} \mathrm{C} \cdot \mathrm{min}^{-1}$ from ambient temperature to $550^{\circ} \mathrm{C}$.

For the TGA-FTIR study, the TGA was interfaced with a Nicolet FTIR spectrometer using TGA-FTIR interface. The infrared (IR) cell and the heated line transferring evolved gases from the TGA to the FT IR were maintained at $225^{\circ} \mathrm{C}$ and $215^{\circ} \mathrm{C}$, respectively. IR spectra were recorded in the spectral range of $4,000-500 \mathrm{~cm}^{-1}$ with a $4 \mathrm{~cm}^{-1}$ resolution throughout the degradation analyses.

\section{Results and discussions}

Syntheses and characterizations of multiallyl-functionalized polyurethanes

The properties of PUs mainly depend on properties, compositions, and structures of their soft/hard segments. In this study,
PLA and PHB oligomers, having soft segments with welldefined molar masses, were used in PU syntheses. Hydroxy telechelic PLA and PHB oligomers were first synthesized and characterized.

\section{Syntheses and characterizations of PLA/PHB dihydroxy telechelic oligomers}

The syntheses of PLA (or PHB) dihydroxy telechelic oligomers are illustrated in Figure 1. Dihydroxyl-terminated PLA oligomers were obtained by tin(II) 2-ethylhexanoate catalyzed lactide ring opening polymerization (ROP) with $\mathrm{BD}$ as dialcohol coinitiator. Dihydroxyl-terminated PHB was prepared by transesterification between a commercially available $\mathrm{PHB}$ and $\mathrm{BD}$ using $p$-toluenesulfonic acid as a catalyst.

The obtained products were analyzed by ${ }^{1} \mathrm{H}$ NMR and are depicted in Figures 3 and 4 and Tables 1 and 2.

Figure 3 shows the possible structure and the ${ }^{1} \mathrm{H}$ NMR spectra of the dihydroxyl telechelic PLA synthesized with different (PLA)/(BD) mole ratios. The quartet at $4.35 \mathrm{ppm}$ and the multiplet at $5.2 \mathrm{ppm}$ correspond to protons a and $\mathrm{a}^{\prime}$ from main/end chain methines of PLA repeat units. The ratio $\left[\left(a+a^{\prime}\right) / a^{\prime}\right]$ represents the polymerization degree of the oligomer. It is clear that this ratio decreased when the (LLA)/(BD) ratio decreased. The molar mass of the oligomers calculated from ${ }^{1} \mathrm{H}$ NMR spectra listed in Table 1 is in accordance with SEC results. Furthermore, if the ratio of (LLA)/(BD) is less than 4, some hydroxyl group from BD did not initiate the ROP and generated adjacent methylene proton $b$ (Figure 4). The obtained PLA oligomers were used for the PU synthesis immediately after the polymerization because of its hydrophilicity. ${ }^{24}$

The ${ }^{1} \mathrm{H}$ NMR spectra of the dihydroxyl telechelic PHB oligomer prepared by transesterification with dialcohol are shown in Figure 4. The molar mass of a PHB oligomer can be controlled by adjusting the transesterification reaction time.

Transesterification of PHB and BD leads to the formation of mass-reduced telechelic oligomers. Their structures are shown in Figure 1. Comparing the commercial PHB to the prepared PHB oligomers, new protons belonging to 1,4-butandiol attached on the oligomer end chain are obtained: d (triplet), e (triplet), and $\mathrm{f}$ and $\mathrm{g}$ (multiplets). The sextets a and $a^{\prime}$ represent the methine protons of the PHB repeat unit. Therefore, the polymerization degree can be calculated as the ratio $2\left(\mathrm{a}+\mathrm{a}^{\prime}\right) / \mathrm{e}$. As expected, the $\mathrm{Dp}_{\mathrm{n}}$ decreased with reaction time. ${ }^{1} \mathrm{H}$ NMR results are depicted in Table 2 . 


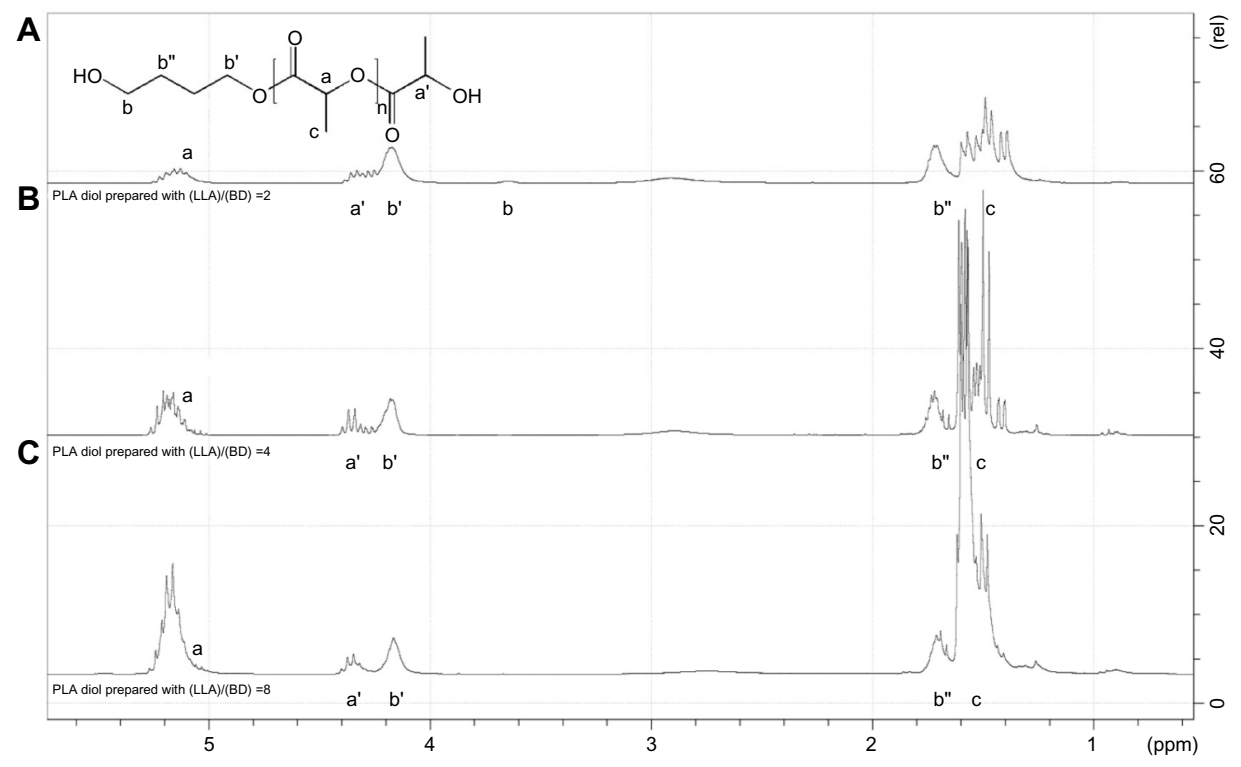

Figure 3 The 'H NMR spectrum of telechelic hydroxylated PLA oligomer with different (LLA)/(BD) feeding ratios in $\mathrm{CDCl}_{3}$, from 3.0 to 5.5 ppm. Notes: (A) $(\mathrm{LLA}) /(\mathrm{BD})=8 ;(\mathrm{B})(\mathrm{LLA}) /(\mathrm{BD})=4 ;(\mathrm{C})(\mathrm{LLA}) /(\mathrm{BD})=2$.

Abbreviations: PLA, polylactic acid; LLA, 3,6-dimethyl-1,4-dioxane-2,5-dione L-lactide; BD, 1,4-butanediol.

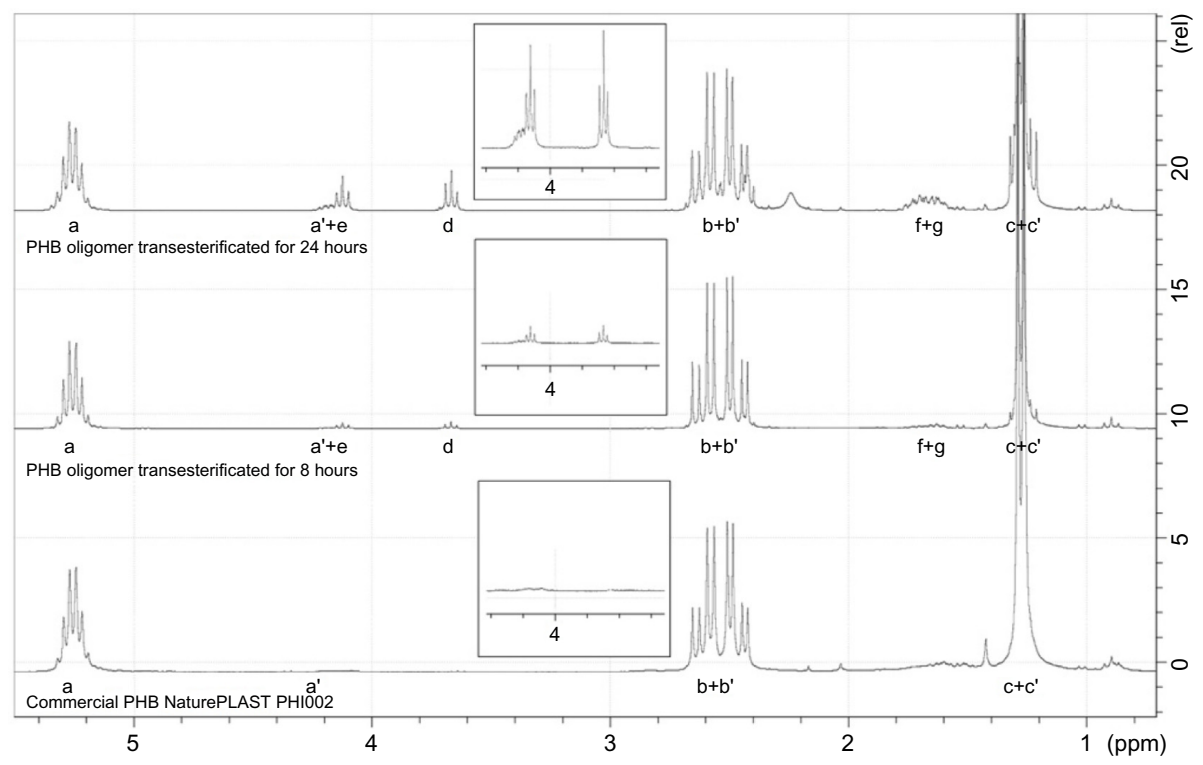

Figure 4 The 'H NMR spectrum of purified telechelic hydroxylated PHB oligomer from I to $5 \mathrm{ppm}$. The experiment was performed at $70^{\circ} \mathrm{C}$ with chloroform reflux. Abbreviations: PHB, polyhydroxybutyrate; NMR, nuclear magnetic resonance.

Table I Molar mass and $T_{\mathrm{g}}$ of hydroxyl telechelic PLA oligomers synthesized with different (LLA)/(BD) ratios

\begin{tabular}{llll}
\hline Ratio of $(\mathbf{L L A}) /(\mathbf{B D})(\mathbf{m o l} / \mathbf{m o l})$ & $\mathbf{8}$ & $\mathbf{4}$ & $\mathbf{2}$ \\
\hline Theoretical $M_{\mathrm{n}}\left(\mathrm{g} \cdot \mathrm{mol}^{-1}\right)$ & 1,387 & $8 \mathrm{Il}$ & $622.5 \mathrm{I}$ \\
$M_{\mathrm{n}}$ by SEC $\left(\mathrm{g} \cdot \mathrm{mol}^{-1}\right)$ & 2,242 & 1,060 & $68 \mathrm{I}$ \\
$M_{\mathrm{n}}$ by 'H NMR $\left(\mathrm{g} \cdot \mathrm{mol}^{-1}\right)$ & $\mathrm{I}, 684$ & 860 & 537 \\
$T_{\mathrm{g}}$ by DSC $\left({ }^{\circ} \mathrm{C}\right)$ & 4.67 & -14.6 & -28.8 \\
\hline
\end{tabular}

Note: Polymerizations were performed at $130^{\circ} \mathrm{C}$ for 3 hours.

Abbreviations: $T_{g}$, glass transition temperature; PLA, polylactic acid; LLA, 3,6dimethyl-I,4-dioxane-2,5-dione L-lactide; BD, I,4-butanediol; $M_{n}$, number average molar mass; SEC, size exclusion chromatography; NMR, nuclear magnetic resonance; DSC, differential scanning calorimetry.
Table 2 Molar mass and $T_{g}$ of hydroxyl telechelic PHB oligomers synthesized with esterification temperatures

\begin{tabular}{llll}
\hline Samples & $\begin{array}{l}\text { PHB } \\
\text { (PHI002) }\end{array}$ & $\begin{array}{l}\text { PHB } \\
\text { oligomer I }\end{array}$ & $\begin{array}{l}\text { PHB } \\
\text { oligomer 2 }\end{array}$ \\
\hline $\begin{array}{l}\mathrm{M}_{\mathrm{n}} \text { by }{ }^{\prime} \mathrm{H} \text { NMR } \\
\left(\mathrm{g} \cdot \mathrm{mol}^{-1}\right)\end{array}$ & 4,230 & $\mathrm{I}, 470$ & 980 \\
$T_{\mathrm{g}}$ by DSC $\left({ }^{\circ} \mathrm{C}\right)$ & 1.9 & 1.4 & -0.8
\end{tabular}

Note: Transesterifications were performed for 24 hours.

Abbreviations: $T_{g}$, glass transition temperature; PHB, polyhydroxybutyrate; $M_{n}$, number average molar mass; NMR, nuclear magnetic resonance; DSC, differential scanning calorimetry. 


\section{Syntheses and characterizations}

of multi-allyl-functionalized polyurethanes

By designing the structures of the telechelic PLA- or PHBsegmented PUs and structures, including hard/soft segment composition, the double-bond functionality of the PUs could be changed as well as the methacrylated networks based on these PUs. Different structures were designed; an example is given in Figure 5.

Miller-Macosko equations 1-3 were used to avoid cross-linking of the reactive system, fixing gel conversion to a higher value than 1 (typically 1.05). ${ }^{25}$ Formulae of PUs synthesized in this study are listed in Table 3:

$$
\begin{aligned}
& P_{\text {gel }}^{2}=\frac{1}{\left(\bar{f}_{A}-1\right)\left(\bar{f}_{B}-1\right)} \times \frac{1}{r} \\
& \overline{f_{i}}=\frac{\sum n_{i} f_{1}^{2}}{\sum n_{i} f_{i}} \\
& r=\frac{n_{A} f_{A}}{n_{B} f_{B}}
\end{aligned}
$$

As shown in Table 3, from Run 1 to Run 3 (or Runs 8, 9, and 10 for PHB systems), the tri-functionalized PU was segmented with a different number of the same degradable oligomers. The group including Runs 3, 4, and 5 (or Runs 10 and 11 for the PHB system) is designed by using the same number of degradable segments but with different molar masses in synthesizing tri-functionalized PUs. When comparing Runs 3, 6, and 7 (or Runs 8, 12, and 13 for the PHB system), different functionalities of these PUs were expected. These three groups were designed to alter the hard/soft segment compositions and the double-bond functionalities of the PUs.

\section{Monitoring of the synthesis of multi-allyl- functionalized polyurethanes by FTIR}

Syntheses of PUs were monitored by FTIR as illustrated in Figure 6. $\mathrm{C}-\mathrm{H}$ stretching absorption of methyl groups approximately $3,000 \mathrm{~cm}^{-1}$ was used as the constant peak. The first stage of the synthesis was performed at $80^{\circ} \mathrm{C}$. After 55 minutes, the absorption at approximately 2,263 $\mathrm{cm}^{-1}$ (assigned to the $\mathrm{N}=\mathrm{C}=\mathrm{O}$ group) stopped decreasing and became constant. The elimination of the absorption at $3,476 \mathrm{~cm}^{-1}$ (assigned to the $-\mathrm{OH}$ group) and the appearance of the absorption peak at approximately $3,350 \mathrm{~cm}^{-1}$ (assigned to the - NH group) confirmed the consumption of the alcohols. Then, allylamine was added to the reactive system. The second step was achieved when the $\mathrm{N}=\mathrm{C}=\mathrm{O}$ absorption at $2,263 \mathrm{~cm}^{-1}$ completely disappeared.

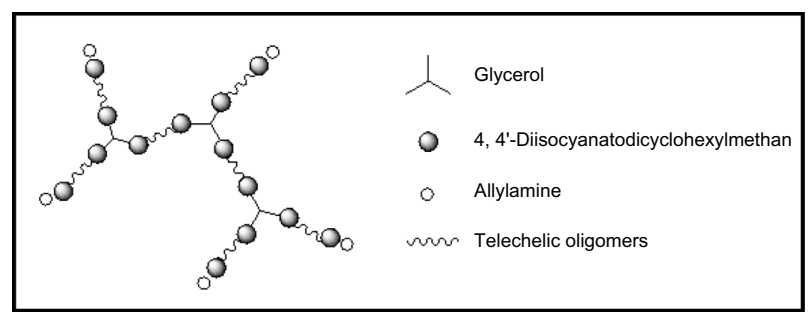

Figure 5 Polyurethane structure with double-bond functionality equal to 5 .

Note: The mole ratio of each component is $\left(\mathrm{H}_{12} \mathrm{MDI}\right)$ :(glycerol):(telechelic oligomer):(allylamine) $=$ 17.65:3:7:5.

Abbreviation: $\mathrm{H}_{12} \mathrm{MDI}, 4,4^{\prime}$-methylenebis(cyclohexyl isocyanate).

\section{Qualitative characterizations of multi-allyl-} functionalized polyurethanes by 'H NMR

The obtained PUs were precipitated twice in large amounts of diethyl ether to remove the unreacted reagents. Then they were dried under vacuum and analyzed by ${ }^{1} \mathrm{H}$ NMR. An example is shown in Figure 7.

${ }^{1} \mathrm{H}$ NMR spectra of polymers are presented in Figure 7 to confirm the PU structures. Each component of the PUs can be easily recognized. For PLA-segmented PU, the methyl and methine protons from the lactide repeat unit can be located as $g$ and $f$ at 1.5 and $5.2 \mathrm{ppm}$, respectively. For PHBsegmented PU, protons from methyl and methylene as well as methine protons from its hydroxybutyric repeat unit can be recognized at 1.2, 2.5, and $5.2 \mathrm{ppm}$, labeled as $\mathrm{j}$, h, and i, respectively. For both systems, the methylene proton of BD segments can also be found as $\mathrm{d}$ and e on the spectra. The intensive multiplet from 0.8 to $2.1 \mathrm{ppm}$ is attributed to the protons of $\mathrm{H}_{12} \mathrm{MDI}$ cyclohexyl rings, with the methine proton $\mathrm{c}$ adjacent to the urethane linkage that can be found at 3.4 ppm. Protons from allyl functions can also be found at 5.2 and $5.8 \mathrm{ppm}$ as $\mathrm{b}$ and $\mathrm{a}$.

For the PLA-based PU, the PLA protons $\mathrm{f}$ and $\mathrm{g}$ were overlapped by other protons, so the 1,4-butandiol methylene proton $\mathrm{d}$ was used to evaluate the mole ratio [LA]/[allyl].

$$
r_{\mathrm{PLA}}=[\mathrm{LA}] /[\text { allyl }]=\mathrm{d} N / 4 \mathrm{a},
$$

where $N$ is the $\mathrm{Dp}_{\mathrm{n}}$ of PLA.

For the PHB-based PU, the mole ratio of PHB repeat units to allyl functions can be evaluated as the ratio of methylene protons of PHB to allyl protons:

$$
r_{\mathrm{PHB}}=[\mathrm{PHA}] /[\mathrm{allyl}]=\mathrm{j} / 2 \mathrm{a}
$$

Some results are listed in Table 4.

Comparing the expected ratio to the real ratio from the obtained product by ${ }^{1} \mathrm{H}$ NMR analyses, the values are very close to each other, proving the expected structure by formula design. 
Table 3 Formulae and compound details for polyurethane syntheses

\begin{tabular}{|c|c|c|c|c|}
\hline Entry & $\begin{array}{l}\text { Expected } \\
\text { double-bond } \\
\text { functionality }\end{array}$ & $\begin{array}{l}\text { Degradable } \\
\text { segment numbers in } \\
\text { expected structures }\end{array}$ & $\begin{array}{l}M_{n} \text { of degradable } \\
\text { segment }\left(\mathrm{g} \mathrm{mol}^{-1}\right)\end{array}$ & $\begin{array}{l}\text { Mole ratio of the reagents } \\
\left(\mathrm{H}_{12} \mathrm{MDI}: \text { glycerol:PLA }\right. \\
\text { [or PHB]:allylamine })\end{array}$ \\
\hline Run I & 3 & $I$ & PLA/870 & $4.41: 1: 1: 3$ \\
\hline Run 2 & 3 & 2 & PLA/870 & $5.52: 1: 2: 3$ \\
\hline Run 3 & 3 & 3 & PLA/870 & $6.62: 1: 3: 3$ \\
\hline Run 4 & 3 & 3 & PLA/530 & $6.62: 1: 3: 3$ \\
\hline Run 5 & 3 & 3 & PLA/I,680 & $6.62: 1: 3: 3$ \\
\hline Run 6 & 5 & 7 & PLA/870 & | 7.65:3:7:5 \\
\hline Run 7 & 7 & 11 & PLA/870 & 28.7:5:1 I:7 \\
\hline Run 8 & 3 & 1 & $\mathrm{PHB} / 980$ & 4.4I:1:1:3 \\
\hline Run 9 & 3 & 2 & $\mathrm{PHB} / 980$ & $5.52: 1: 2: 3$ \\
\hline Run 10 & 3 & 3 & $\mathrm{PHB} / 980$ & $6.62: 1: 3: 3$ \\
\hline Run II & 3 & 3 & $\mathrm{PHB} / \mathrm{I}, 470$ & $6.62: 1: 3: 3$ \\
\hline Run 12 & 5 & 7 & $\mathrm{PHB} / 980$ & | $7.65: 3: 7: 5$ \\
\hline Run 13 & 7 & 11 & $\mathrm{PHB} / 980$ & 28.7:5:1 I:7 \\
\hline
\end{tabular}

Abbreviations: $M n$, number average molar mass; $\mathrm{H}_{12}$ MDI, 4,4'-methylenebis(cyclohexyl isocyanate); PLA, polylactic acid; PHB, polyhydroxybutyrate.

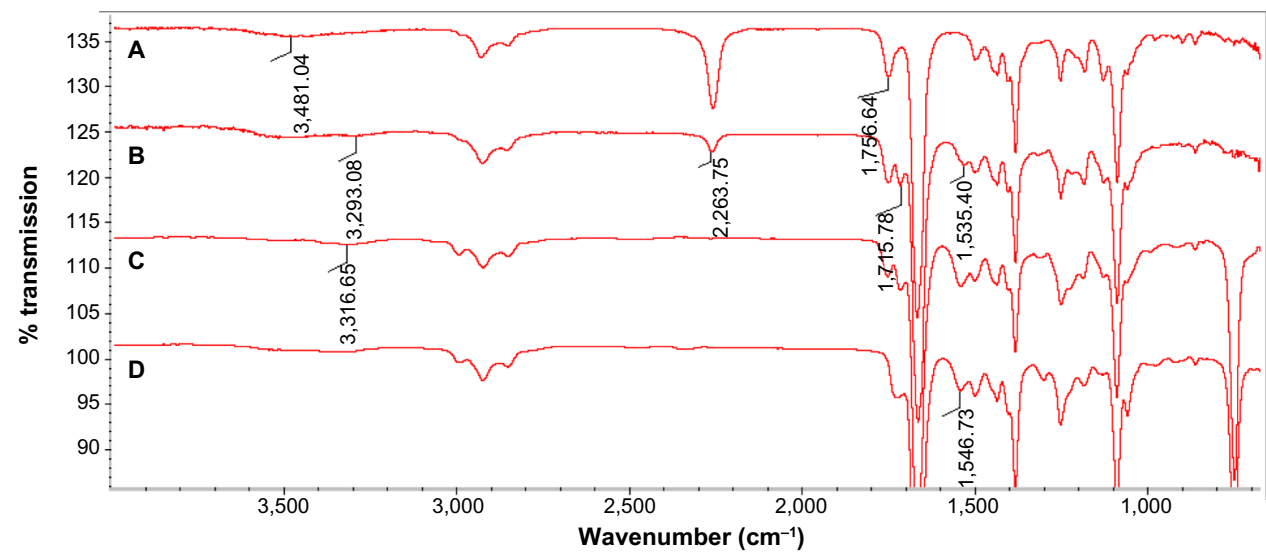

Figure 6 FTIR spectra for the monitoring of the allyl-functionalized polyurethane syntheses.

Notes: For PLA-segmented PU Run 3: (A) reagents at initial time, (B) PLA-segmented PU prepolymer after the first step of synthesis, (C) allyl-functionalized PLA-segmented PU after the second step; for PHB-segmented PU Run 10 (D) allyl-functionalized PHB PU after the second step.

Abbreviations: FTIR, Fourier transform infrared; PLA, polylactic acid; PU, polyurethane; PHB, polyhydroxybutyrate.

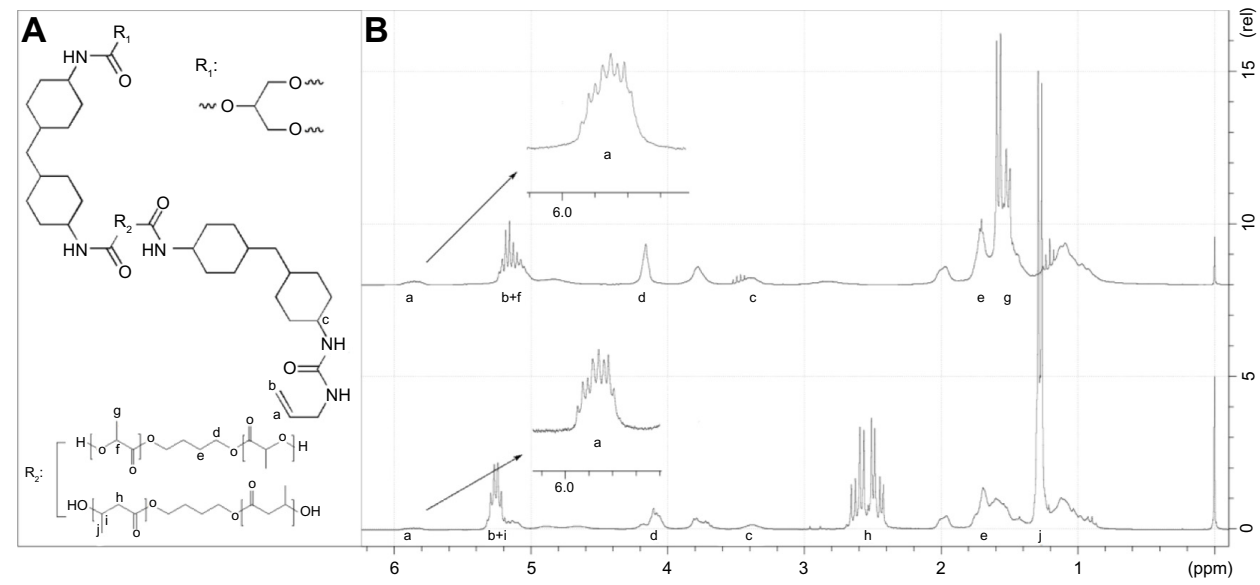

Figure 7 The expected structure of allyl-functionalized polyurethanes (A) and their 'H NMR spectra (B).

Notes: (B): PLA-based PU for Run 3 (upper) and PHB-based PU for Run II (lower) in $\mathrm{CDCl}_{3}$. All the samples were purified before the analyses. The arrows point to a spectral part enlargement.

Abbreviations: NMR, nuclear magnetic resonance; PLA, polylactic acid; PU, polyurethane; PHB, polyhydroxybutyrate. 


\section{SEC and DSC analyses of multi-allyl-functionalized} polyurethanes

To further evaluate the structures of the products, these allyl-functionalized PUs were analyzed by SEC. The results are listed in Table 5. The molar masses of the PUs can be affected by three factors: functionality, number of the degradable segments, and molar masses of these segments. As expected, the molar masses of the PUs increased when each of these factors increased.

Glass transition temperatures $\left(T_{\mathrm{g}}\right)$ of these allylfunctionalized PUs were measured by DSC (Table 5). The PLA-segmented PUs have the same $T_{\mathrm{g}}$ values. These $T_{\mathrm{g}}$ values are, as expected, higher than the $T_{\mathrm{g}}$ of PLA oligomers used in the PU synthesis (Table 1) because of the presence of urethane functions that harden the polymer chains and also induce hydrogen bonds. The product obtained in Run 5 (PU with PLA $M_{\mathrm{n}}=1,680 \mathrm{~g} \mathrm{~mol}^{-1}$ ) has a $T_{\mathrm{g}}$ obviously lower than the others. This difference is the result of longer PLA chain and PCL content that decrease the hard segment content and consequently result in fewer hydrogen bonds. For PHB-segmented PUs as well, the $T_{\mathrm{g}}$ values of the poly(esterurethane)s shift toward the $T_{\mathrm{g}}$ of PHB when the PHB content increases.

\section{Methacrylated PU copolymer networks' syntheses and thermal characterizations}

2-Hydroxyl ethyl methacrylate was used as co-monomer and also as reactive solvent of the prepolymers whose preparation is explained in "Syntheses and characterizations" section, shown in Figure 2. A mass ratio of $M_{\mathrm{HEMA}}: M_{\mathrm{PU}}=1.5: 1$ was used for all samples and the copolymerizations were UV initiated. The obtained products became insoluble in THF and chloroform as a result of cross-linking.

Table 4 The average ratio of repeat units to double-bond functions in allyl-functionalized polyurethane moles, by idea value and by real value, respectively

\begin{tabular}{lllll}
\hline Samples & Run 3 & Run 6 & Run 7 & Run I I \\
\hline $\begin{array}{l}\text { Functionality of expected } \\
\text { structured PUs }\end{array}$ & 3 & 5 & 7 & 3 \\
$\begin{array}{l}\text { Expected (allyl function)/(LA } \\
\text { or HB) repeat unit, mol:mol }\end{array}$ & I:4N & I:5.6N & I:6.2N & I:48.0 \\
$\begin{array}{l}\text { Calculated (allyl function)/ } \\
\text { (LA or HB) repeat unit by }\end{array}$ & I:3.8N & I:5.3N & I:6.4N & I:46.4 \\
'H NMR results, mol:mol & & & & \\
\hline
\end{tabular}

Note: All polymerizations were performed with $0.5 \mathrm{~mol} \%$ of DBTDL at $80^{\circ} \mathrm{C}$ for 60 minutes for the first step, and at $0^{\circ} \mathrm{C}$ for 30 minutes for the second step.

Abbreviations: DBTDL, dibutyltin dilaurate; PUs, polyurethanes; LA, lactic acid; $\mathrm{HB}$, hydroxybutyrate; NMR, nuclear magnetic resonance.

\section{PU/PHEMA networks by DSC}

The obtained PU/PHEMA networks were analyzed by DSC. Results are given in Table 6. For all samples, only one glass transition was observed, indicating the homogeneity of the networks and the good compatibility of the PUs and PHEMA.

For all the data illustrated in Table 6, it can be seen that the cross-linking ability of the PU obviously affects the glass transition of the network.

Investigating networks formed by PLA-segmented PUs, samples from Runs 17, 16, and 18 were based on the PUs from Run 4 (PLA, $M_{\mathrm{n}}=530 \mathrm{~g} \mathrm{~mol}^{-1}$ ), Run 3 (PLA, $M_{\mathrm{n}}=870 \mathrm{~g}$ $\mathrm{mol}^{-1}$ ), and Run $5\left(\mathrm{PLA}, M_{\mathrm{n}}=1,680 \mathrm{~g} \mathrm{~mol}^{-1}\right)$, respectively. In this group, Run 4 has the lowest PLA content and the highest double-bond concentration, so the network based on Run 4 has the highest $T_{\mathrm{g}}$ when compared with other networks. On the contrary, Run 5 has a higher PLA content which leads to its lower $T_{\mathrm{g}}$ and a lower double-bond concentration. When synthesizing the network with this PU, the obtained network shows almost no increase of its glass transition temperature. Similar trends can be observed when comparing Runs 14, 15, and 16 based on PUs from Run 1 (1 PLA segment), Run 2 (two segments), and Run 3 (three segments). Although these three PU have similar $T_{\mathrm{g}}$ values, the network from Run 14 based on PU from Run 1 with more cross-linkable double bonds shows a higher $T_{\mathrm{g}}$ than the network from Run 16 based on Run 3. When comparing PUs with different functionalities, PUs from Run $6(f=5)$ and Run 7 $(f=7)$ have similar compositions and double-bond concentrations, so the networks based on these have the same $T_{\mathrm{g}}$.

The PHB-segmented PU-based networks illustrate more clearly the conclusion drawn just above: the network from Run 21 composed of Run 8 (1 PHB segment) shows a completely different $T_{\mathrm{g}}$, higher than in the other networks, while the network from Run 23 and PU from Run 10 have almost the same $T_{\mathrm{g}}$ due to a low double- bond quantity in the PU from Run 10. Networks from Runs 25 and 26 have even lower $T_{\mathrm{g}}$ values because the PUs from Run $12(f=5)$ and Run $13(f=5)$ have the lowest double-bond concentrations among all PUs. From the data listed above, it can be seen that the $T_{\mathrm{g}}$ of the network mainly depends on the cross-linking density provided by PUs with different double-bond concentrations and the $T_{\mathrm{g}}$ of the PU.

\section{Thermal degradation of the polyurethane/PHEMA networks monitored by TGA-FTIR}

Thermal degradation should be considered when a biomaterial must be processed at high temperatures, such as in extrusion or injection molding. Representative specimens were analyzed in this part. 
Table 5 Molar mass obtained from SEC analyses and glass transition temperature by DSC analyses for the multi-allyl-functionalized polyurethanes

\begin{tabular}{|c|c|c|c|c|c|}
\hline Entry & $\begin{array}{l}(\mathrm{NCO}) /(\mathrm{OH}) \\
\mathrm{mol} / \mathrm{mol}\end{array}$ & $M_{n} / M_{w}$ & $\begin{array}{l}\text { Degradable segment } \\
\text { content (wt\%) }\end{array}$ & $\begin{array}{l}\text { Double-bond } \\
\text { content }\left(\mathrm{mmol} \mathrm{g} \mathrm{g}^{-1}\right)\end{array}$ & $T_{g}\left({ }^{\circ} \mathrm{C}\right)$ \\
\hline Run I & 1.60 & $7,620 / 14,620$ & 37.9 & 1.31 & 53.9 \\
\hline Run 2 & 1.43 & $7,160 / 15,060$ & 50.3 & 0.87 & 47.4 \\
\hline Run 3 & 1.33 & $9,730 / 25,020$ & 56.6 & 0.65 & 49.2 \\
\hline Run 4 & 1.33 & $7,520 / 22,350$ & 44.6 & 0.83 & 59.0 \\
\hline Run 5 & 1.33 & II,780/32,620 & 71.6 & 0.42 & 27.5 \\
\hline Run 6 & 1.22 & $1 \mathrm{I}, 500 / 35,670$ & 53.9 & 0.44 & 46.1 \\
\hline Run 7 & 1.19 & $16,800 / 47,400$ & 53.2 & 0.39 & 46.0 \\
\hline Run 8 & 1.60 & $3,972 / 10,270$ & 40.8 & 1.25 & 18.5 \\
\hline Run 9 & 1.43 & $4,880 / I I, 100$ & 53.4 & 0.81 & 7.8 \\
\hline Run 10 & 1.33 & $5,185 / 9,502$ & 59.5 & 0.61 & 13.2 \\
\hline Run II & 1.33 & $13,470 / 37,870$ & 68.7 & 0.46 & 1.7 \\
\hline Run 12 & 1.22 & $5,926 / 10,429$ & 56.9 & $0.4 \mathrm{I}$ & 2.7 \\
\hline Run 13 & 1.19 & $6,868 / 14,860$ & 56.2 & 0.36 & 2.6 \\
\hline
\end{tabular}

Notes: All polymerizations were performed with $0.5 \mathrm{~mol} \%$ of DBTDL at $80^{\circ} \mathrm{C}$ for 55 minutes for the first step and at $0^{\circ} \mathrm{C}$ for 30 minutes for the second step. All samples were purified before the analyses.

Abbreviations: SEC, size exclusion chromatography; DBTDL, dibutyltin dilaurate; DSC, differential scanning calorimetry; $M_{n}$, number-average molecular weight; $M_{w}$, weightaverage molecular weight; $T_{g}$, glass transition temperature.

\section{Thermal degradation of telechelic PLA and PHB oligomers}

Figure 8 shows the thermal degradation process of the PLA oligomer with molar mass of $870 \mathrm{~g} \mathrm{~mol}^{-1}$ (resulting from ${ }^{1} \mathrm{H}$ NMR analysis in Table 1). From TGA and DTGA (differential TGA) curves, it can be seen that the degradation of the PLA oligomer starts at $180^{\circ} \mathrm{C}$ and reaches its maximum degradation rate approximately $300^{\circ} \mathrm{C}$.

Corresponding with the TGA and DTGA curves, the Gram-Schmidt trace shows the degradation product of PLA oligomers. According to the spectra of the coupled FTIR, lactide is discovered as the main degradation product during

Table 6 The polyurethane composition in the network and the $T_{\mathrm{g}}$ of the network obtained by DSC tests

\begin{tabular}{llll}
\hline Entry & $\begin{array}{l}\text { Polyurethane } \\
\text { adapted in } \\
\text { network formation }\end{array}$ & $\begin{array}{l}\text { Degradable } \\
\text { segment } \\
\text { concentration }\end{array}$ & $\begin{array}{l}\boldsymbol{T}_{\text {g }} \text { of the } \\
\text { PU or the } \\
\text { network }\left({ }^{\circ} \text { C) }\right.\end{array}$ \\
\hline Run 14 & Run I & PLA, 15.2 & 62.3 \\
Run 15 & Run 2 & PLA, 20.I & 61.5 \\
Run 16 & Run 3 & PLA, 22.6 & 59.6 \\
Run 17 & Run 4 & PLA, 17.8 & 68.5 \\
Run 18 & Run 5 & PLA, 28.6 & 28.0 \\
Run 19 & Run 6 & PLA, 21.6 & 60.3 \\
Run 20 & Run 7 & PLA, 21.3 & 62.9 \\
Run 21 & Run 8 & PHB, 16.3 & 36.3 \\
Run 22 & Run 9 & PHB, 21.4 & 18.7 \\
Run 23 & Run 10 & PHB, 23.8 & 16.0 \\
Run 24 & Run 11 & PHB, 27.5 & 6.7 \\
Run 25 & Run 12 & PHB, 22.8 & 7.9 \\
Run 26 & Run 13 & PHB, 22.5 & 5.7 \\
\hline
\end{tabular}

Notes: All networks were performed with 3 wt\% of photo initiator and a mass ratio of $M_{\text {HEMA }}: M_{\text {PU }}=1.5: 1$; the mixtures were irritated by UV exposure for 24 hours. Abbreviations: $T_{g}$, glass transition temperature; DSC, differential scanning calorimetry; PU, polyurethane; PLA, polylactic acid; PHB, polyhydroxybutyrate; UV, ultraviolet. the degradation by bands at $3,006 \mathrm{~cm}^{-1}\left(\gamma_{\mathrm{CH}_{3}}\right), 2,949 \mathrm{~cm}^{-1}$ $\left(\gamma_{\mathrm{as}} \mathrm{CH}_{3}\right), 2,891 \mathrm{~cm}^{-1}\left(\gamma_{\mathrm{s}} \mathrm{CH}_{3}\right), 1,790 \mathrm{~cm}^{-1}(\gamma \mathrm{C}=\mathrm{O}), 1,236 \mathrm{~cm}^{-1}$, and $1,116 \mathrm{~cm}^{-1}\left(\gamma_{\mathrm{s}} \mathrm{C}-\mathrm{O}-\mathrm{C}\right)$. Besides, the ring skeletal vibration at $932 \mathrm{~cm}^{-1}$ is a characteristic absorption for the cyclic oligomer that is also shown in lactide FTIR spectra. In contrast to the former research, ${ }^{26}$ the characteristic absorption of acetaldehyde at 3,475 $\mathrm{cm}^{-1}(\gamma \mathrm{C}=\mathrm{O})$ and $2,740 \mathrm{~cm}^{-1}(\gamma \mathrm{CHO})$ was not detected, indicating that aldehyde was not generated during the degradation and neither was carbon monoxide or carbon dioxide generated, with absorptions at $2,350 \mathrm{~cm}^{-1}$ and at 2,170/2,115 $\mathrm{cm}^{-1}$. The $\gamma \mathrm{O}-\mathrm{H}$ band at $3,576 \mathrm{~cm}^{-1}$ is believed to originate from the hydroxyl group of lactide and $\mathrm{BD}$, the coinitiators that ring opening polymerize the lactic acid.

Compared to PLA oligomers, PHB-diol has a higher starting degradation temperature but a narrower degradation range approximately $310^{\circ} \mathrm{C}$, as shown in Figure 9. Degradation of the PHB generates crotonic acid as the main product with absorptions at 3,576 $\mathrm{cm}^{-1}(\gamma \mathrm{O}-\mathrm{H}), 3,056-2,882 \mathrm{~cm}^{-1}(\gamma \mathrm{C}-\mathrm{H})$, 1,768 and $1,752 \mathrm{~cm}^{-1}(\gamma \mathrm{C}=0), 1,660 \mathrm{~cm}^{-1}(\gamma \mathrm{C}=\mathrm{C}), 1,451$ $\mathrm{cm}^{-1}(\gamma \mathrm{C}-\mathrm{H}), 1,357 \mathrm{~cm}^{-1}\left(\gamma \mathrm{CH}_{3}\right), 1,144 \mathrm{~cm}^{-1}$ and $1,093 \mathrm{~cm}^{-1}$ $(\gamma \mathrm{C}-\mathrm{O})$, and $964 \mathrm{~cm}^{-1}(\gamma$ trans $\mathrm{C}=\mathrm{C})$. The absorption at $694 \mathrm{~cm}^{-1}$ is characteristic for the cis configuration of crotonic acid, which corresponds with the former researches. ${ }^{27,28}$

Thermal degradation of allyl-functionalized PLA- or PHB-segmented polyurethanes

The thermal degradations of allyl-functionalized PUs were investigated based on their degradable segment degradation mechanism illustrated earlier. In this study, Run 1 from PLA and Run 8 for PHB systems were chosen for their higher isocyanate contents. The degradation of the isocyanate of 
A

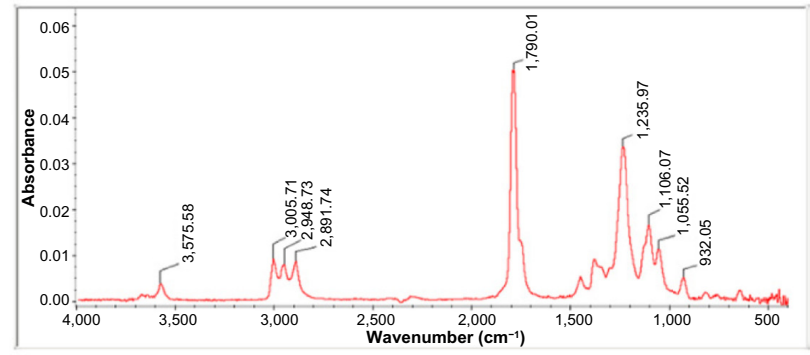

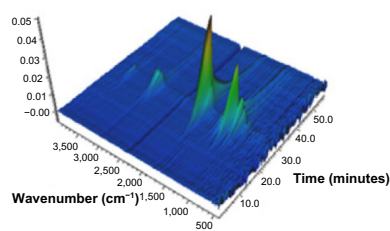

B

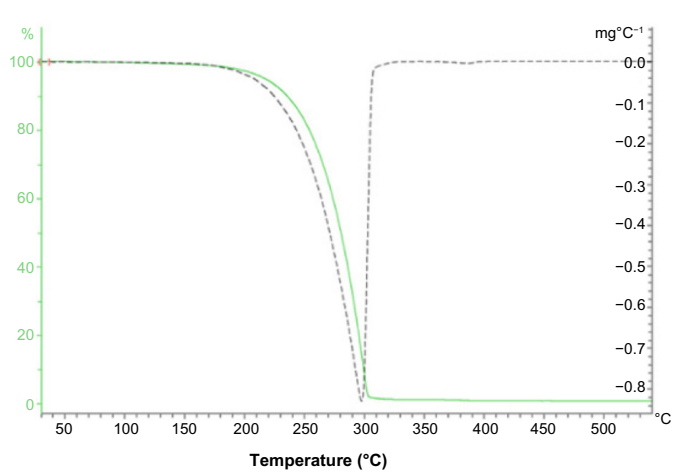

C

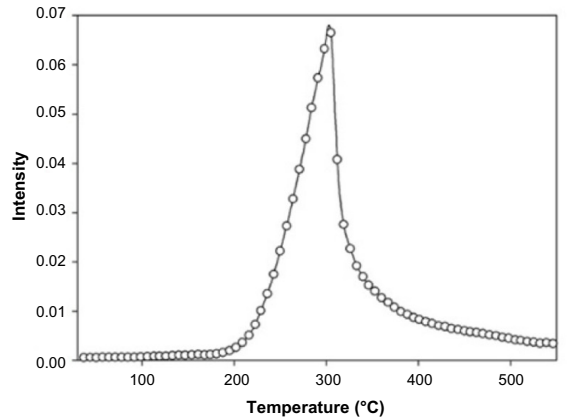

Figure 8 3D FTIR spectra (A), TGA and DTGA (B) and gram-schimdt (C) curves for degradation of PLA oligomer. The PLA oligomer was prepared with a mole ratio (LA)/ $(B D)=8$ at $130^{\circ} \mathrm{C}$ for 3 hours. The IR spectrum top left was collected at $305^{\circ} \mathrm{C}$.

Abbreviations: 3D, three-dimensional; FTIR, Fourier transform infrared; TGA, thermogravimetric analysis; DTGA, derivative thermogravimetric analysis; PLA, polylactic acid.

these PUs can be more clearly shown on the curves. Results are illustrated in Figures 10 and 11.

Figure 10 shows the thermal degradation of the PLA-segmented PU Run 1. For TGA and DTGA and Gram-Schmidt curves, the weight loss below $150^{\circ} \mathrm{C}$ is due to the evaporation of the remaining solvent (DMF).
Compared to the degradation of PLA oligomers, three new degradation steps were shown by the DTGA curve and Gram-Schmit traces approximately $260^{\circ} \mathrm{C}, 340^{\circ} \mathrm{C}$, and $460^{\circ} \mathrm{C}$. Moreover, the degradation step at $260^{\circ} \mathrm{C}$ overlaps the PLA degradation step at a similar temperature range $\left(270^{\circ} \mathrm{C}\right)$. According to previous research, ${ }^{29}$ these three new
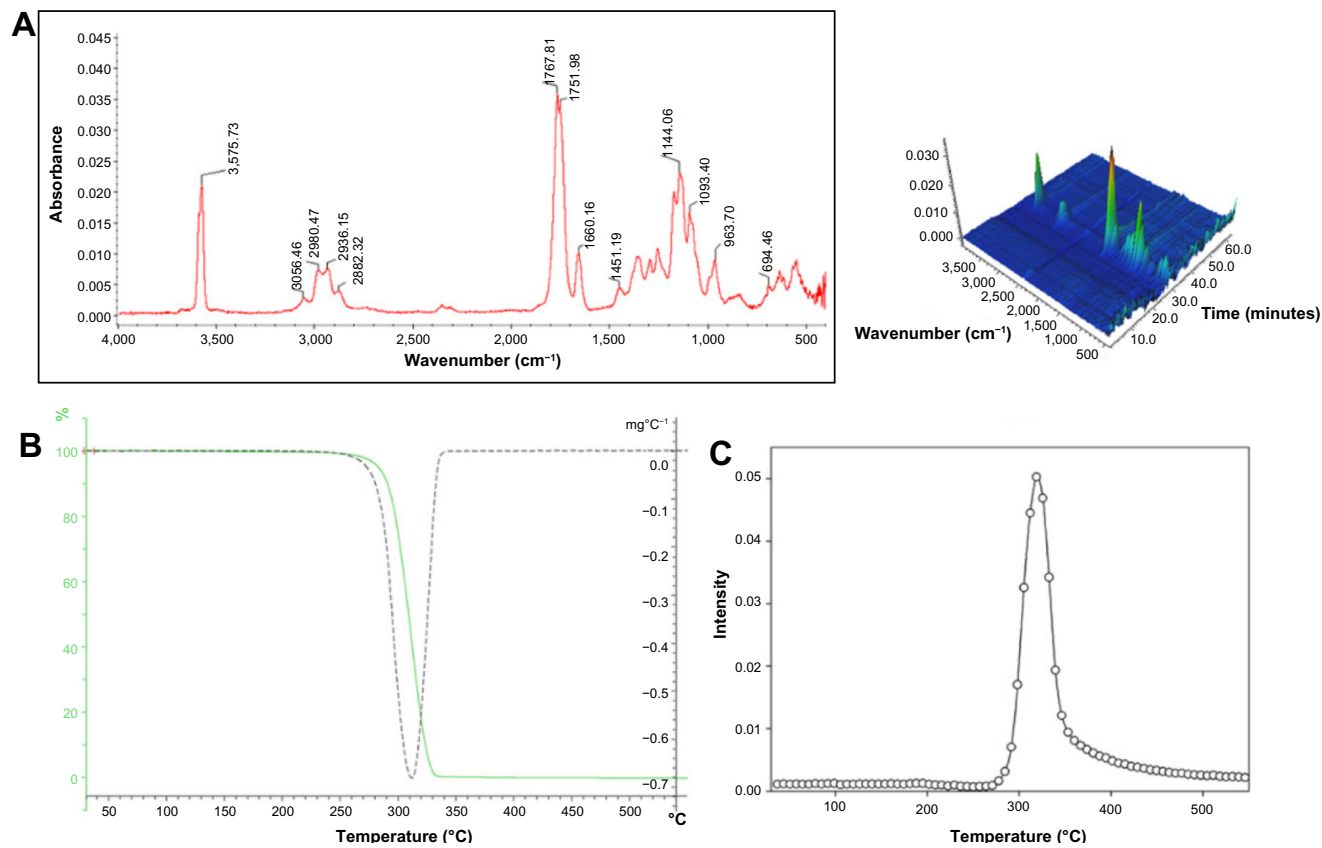

Figure $93 \mathrm{D} \mathrm{FTIR} \mathrm{spectra} \mathrm{(A),} \mathrm{TGA} \mathrm{and} \mathrm{DTGA} \mathrm{(B)} \mathrm{and} \mathrm{gram-schimdt} \mathrm{(C)} \mathrm{curves} \mathrm{for} \mathrm{degradation} \mathrm{of} \mathrm{PHB} \mathrm{oligomer.} \mathrm{The} \mathrm{PHB} \mathrm{oligomer} \mathrm{with} M_{n}=980$ was prepared with chloroform reflux at $70^{\circ} \mathrm{C}$ for 24 hours, as shown in Table 2. The IR spectrum top left was collected at $312^{\circ} \mathrm{C}$.

Abbreviations: 3D, three-dimensional; FTIR, Fourier transform infrared; TGA, thermogravimetric analysis; DTGA, derivative thermogravimetric analysis; PHB, polyhydroxybutyrate. 
degradations belong to the degradation of $\mathrm{H}_{12} \mathrm{MDI}$, including the decomposition of urethane linkage, the continuous degradation of cyclohexyl rings around, and finally the generation of fragments containing amino groups. FTIR spectra shown in Figure 10 are the yielding gaseous products collected at the maximum evolutions in each decomposition step. The spectrum of the product collected at $257^{\circ} \mathrm{C}$ in Figure 10 corresponds to the lactide monomer. At $340^{\circ} \mathrm{C}$, the increase of isocyanate absorptions at $2,260 \mathrm{~cm}^{-1}$ is due to decomposition of the carbamate groups, which happened simultaneously during the degradation of PLA segments, corresponding to the DTGA curve. At $470^{\circ} \mathrm{C}$, the increase of $\mathrm{C}-\mathrm{H}$ absorption approximately $2,900 \mathrm{~cm}^{-1}$ is attributed to the hydrocarbons generated from further degradation of isocyanate fragments, and the absorption centered at $1,520 \mathrm{~cm}^{-1}$ is believed to be the hydrocarbon with amino groups, according to previous reports. ${ }^{29}$ In contrast with those researches, the carbon dioxide absorption at $2,349 \mathrm{~cm}^{-1}$ continues to increase, as shown by IR spectrum collected at $340^{\circ} \mathrm{C}$. It comes from the decomposition of isocyanate groups $(\mathrm{N}=\mathrm{C}=\mathrm{O})$ with considerable amounts in the composition of PU. The degradation of PLA segments was completed, with only little lactide detected at this stage.

Figure 11 shows the PHB-segmented PU thermal degradation. Unlike the thermal degradation of PLA-segmented PUs, the decomposition of the carbamate happened before the degradation of the PHB segment. As shown by IR spectrum at $257^{\circ} \mathrm{C}$ in Figure 11, isocyanate absorption was detected with trace absorption of crotonic acid - the degradation product of PHB that appeared at higher temperatures $\left(260^{\circ} \mathrm{C}-335^{\circ} \mathrm{C}\right)$. The three-step degradation of $\mathrm{H}_{12} \mathrm{MDI}$ can also be seen in DTGA curve and IR spectra at $278^{\circ} \mathrm{C}, 345 / 367^{\circ} \mathrm{C}$, and $470^{\circ} \mathrm{C}$, respectively.

To further investigate the degradation behavior of PLAand PHB-segmented PUs with different compositions, all PUs synthesized in Table 3 were characterized with TGA and compared with each other, with the results being depicted in Figure 12.

When comparing the TGA curves of the PLA-segmented PU in Runs 5 and 3 in Figure 12 (left), it can be seen that PUs having longer degradable segments are more stable than those with shorter chains, but tend to lose more weight in their first degradation step. This point was also confirmed by comparing Run 3 to Run 1 for PLA systems or Run 10 to Run 8 for PHB systems. Furthermore, PUs with more $\mathrm{H}_{12}$ MDI seem more stable than those with fewer counterparts. It can be explained because a higher $\mathrm{H}_{12} \mathrm{MDI}$ content means more carbamate groups in the PUs. Therefore, the more rigid structure and stronger hydrogen bond interaction between carbamate group and carbonyl or hydroxyl groups make the system more thermally stable. These curves indicate that the stability of the PUs depends

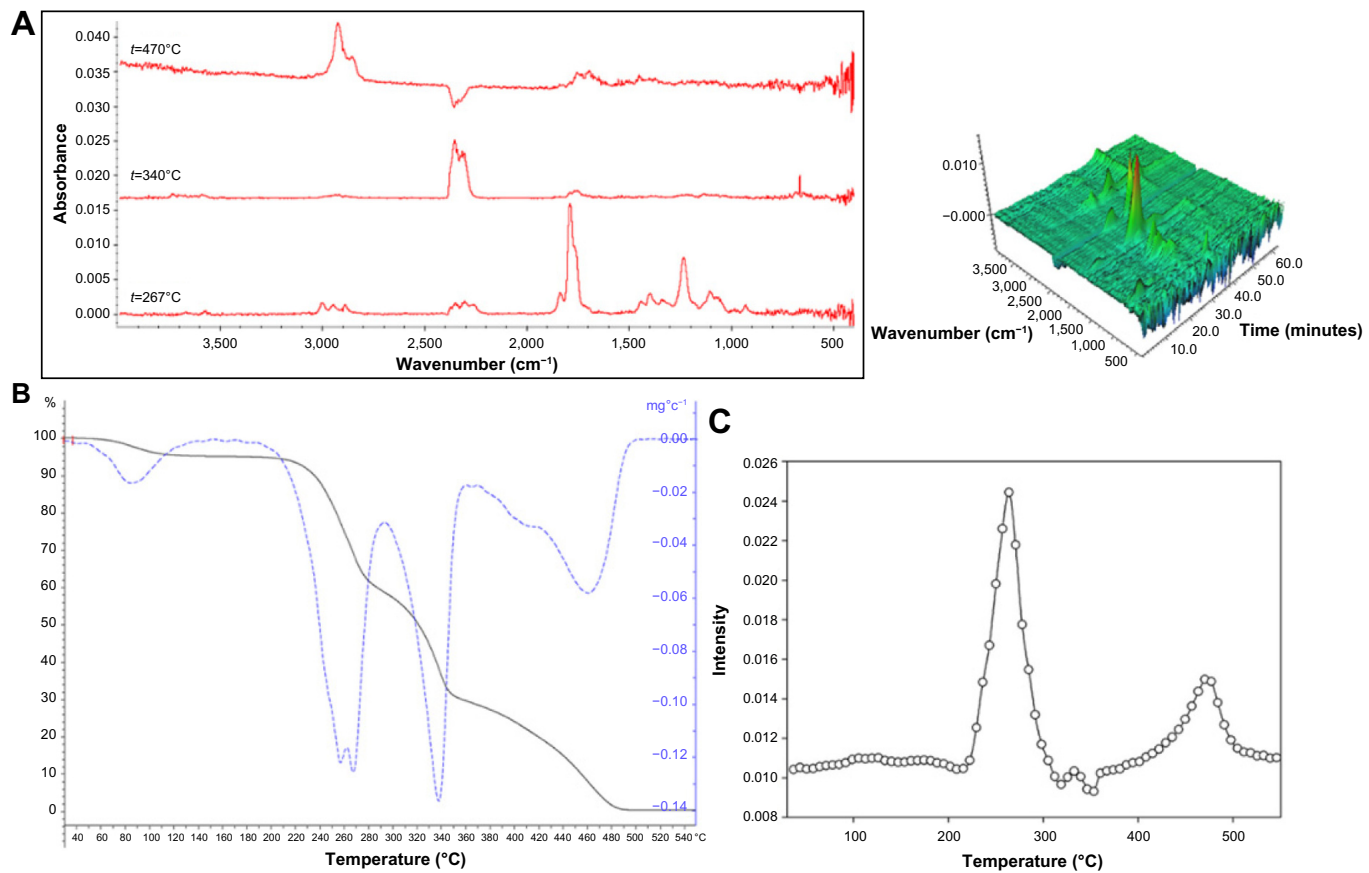

Figure 10 3D FTIR spectra (A), TGA and DTGA (B) and gram-schimdt (C) curves for degradation of PLA-segmented purified polyurethane Run I. The FTIR spectra were obtained at the maximum evolution rate for each decomposition step.

Abbreviations: 3D, three-dimensional; FTIR, Fourier transform infrared; TGA, thermogravimetric analysis; DTGA, derivative thermogravimetric analysis; PLA, polylactic acid. 

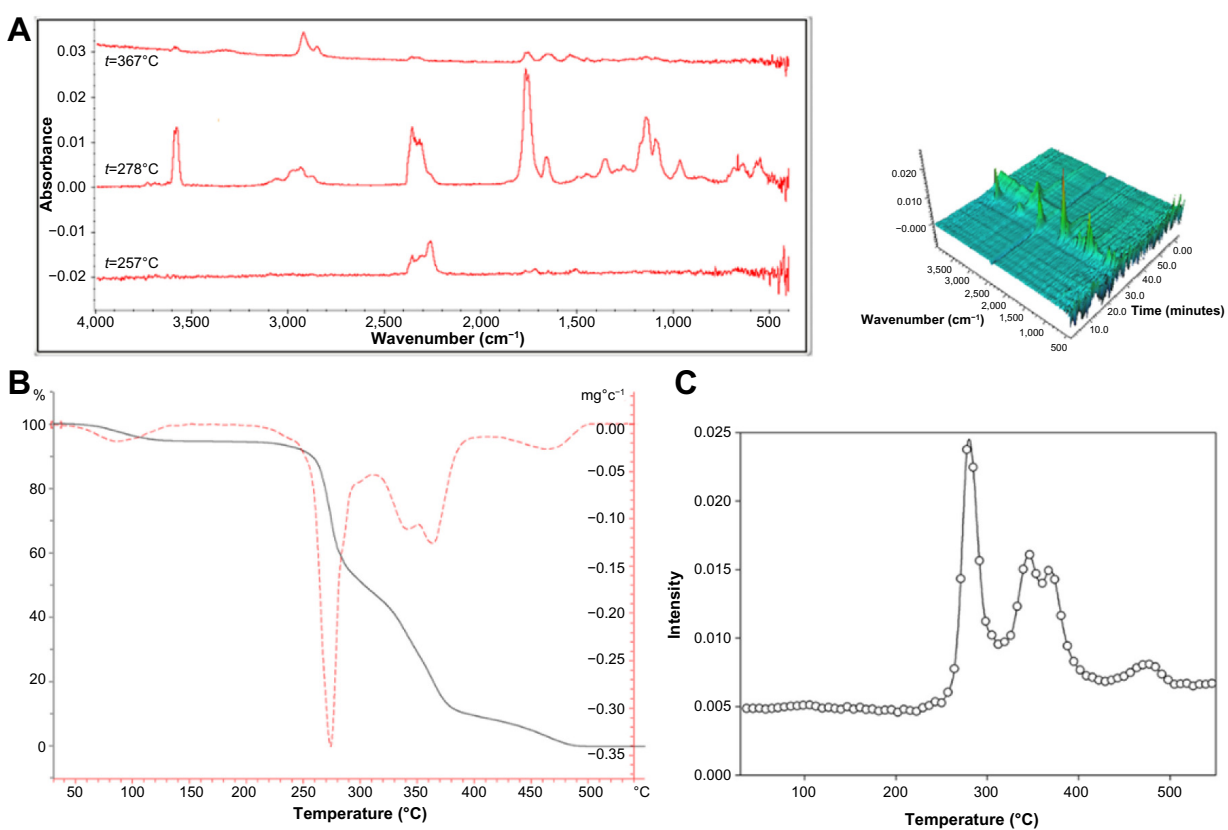

C

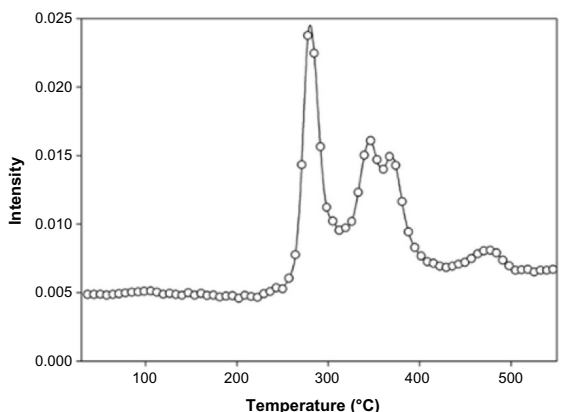

Figure II 3D FTIR spectra (A), TGA and DTGA (B) and gram-schimdt (C) curves for degradation of PHB-segmented polyurethane Run 8 and the FTIR spectra were obtained at the maximum evolution rate for each decomposition step.

Abbreviations: 3D, three-dimensional; FTIR, Fourier transform infrared; TGA, thermogravimetric analysis; DTGA, derivative thermogravimetric analysis; PHB, polyhydroxybutyrate.

mainly on the $\mathrm{H}_{12}$ MDI content and the molar mass of the degradable segments.

For DTGA curves of both systems, PUs having higher degradable contents, eg Runs 5 and 13, are expected to lose weight faster (with the maximum degradation rate shown by DTGA curve) during the first degradation step. On the contrary, the PUs having higher $\mathrm{H}_{12} \mathrm{MDI}$ content showed similar trends during their degradation step approximately $450^{\circ} \mathrm{C}$. This result corresponds to the conclusion of the syntheses part, which proves that the expected structure was obtained through structure design. The functionality of PUs has little effect on their stability since it does not dramatically change
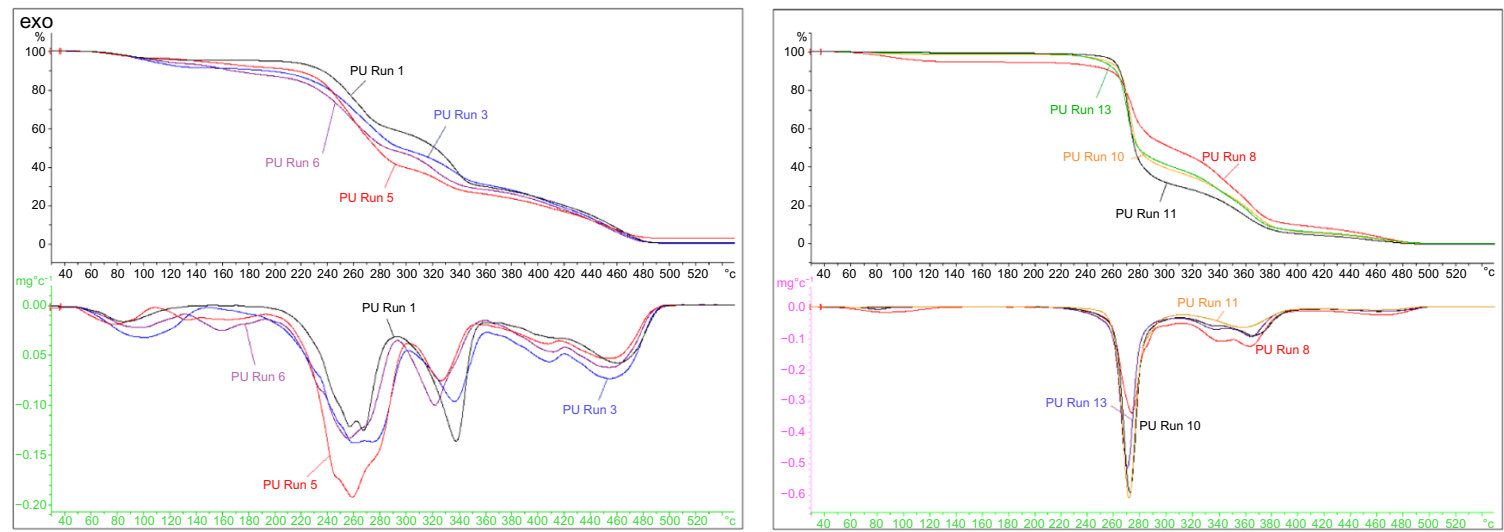

Figure 12 TGA and DTGA curves of polyurethanes synthesized in Table 3.

Notes: Left: PLA-based polyurethanes. Right: PHB-based polyurethanes.

Abbreviations: PU, polyurethane; TGA, thermogravimetric analysis; DTGA, derivative thermogravimetric analysis; PLA, polylactic acid; PHB, polyhydroxybutyrate. the ratio of hard/soft segment composition, shown as the TGA graph in Figure 12.

\section{Thermal degradation of polyurethane/PHEMA networks} Based on the TGA of the multi-allyl-functionalized PUs, these PUs were combined with HEMA to form a biocompatible network through UV-induced radical polymerization with a mass ratio of $M_{\mathrm{HEMA}}: M_{\text {polyurethane }}=1.5: 1$. Thermal degradation of these networks was also performed with TGA-FTIR technology, and the result is depicted in Figures 13-15.

Figure 13 shows the TGA and DTGA curves of the PU/ PHEMA network based on the PU from Run 3. Compared 
with the DTGA curve of the PUs from Run 3, the DTGA curve of the network Run 16 (based on PU Run 3) only shows two maximum degradation peaks on the Gram-Schmidt trace at $260^{\circ} \mathrm{C}$ and $420^{\circ} \mathrm{C}$. The former one is due to the degradation of PLA segments and urethane link decomposition, while the latter one is believed to be caused mainly by the decomposition of the PHEMA chains (also including degradation of $\mathrm{H}_{12} \mathrm{MDI}$ ). The strong weight loss in this stage is consistent with the particularly high content of PHEMA in the network (60 wt \%). Although thermal degradation behavior of PHEMA was discussed with different results, ${ }^{30-34}$ only one degradation step approximately $420^{\circ} \mathrm{C}$ was detected and recognized as the main degradation of PHEMA chains in the $\mathrm{PU}$, which should generate $\mathrm{CH}_{2}=\mathrm{C}\left(\mathrm{CH}_{3}\right) \mathrm{CO}, \mathrm{CH}_{2}=\mathrm{C}\left(\mathrm{CH}_{3}\right)-$, and $\left(\mathrm{CH}_{3}\right)_{2} \mathrm{CHCO}_{2}$ fragments by decomposition. ${ }^{34}$

Compared with the IR spectra of PLA-segmented PUs in Figure 10, bands at 1,738 $\mathrm{cm}^{-1}(-\mathrm{C}=\mathrm{O}), 1,400-1,380 \mathrm{~cm}^{-1}$ $\left(-\mathrm{CH}_{2}\right)$ in Figure 13 can be recognized as the absorption of HEMA - the degradation product of PHEMA chains and correspond with the former results mentioned above. However, peaks at 1,637 and $816 \mathrm{~cm}^{-1}$ corresponding to double-bond absorptions for HEMA are not obvious in the polymer spectrum.

Similar trends can be found in Figure 14 concerning the degradation of PHB-PU-based networks. Contrary to the degradation of PHB-based PU shown in Figure 11, the
DTGA curve in Figure 14 (the degradation of PHB-PU-based networks) shows fast weight loss, approximately $450^{\circ} \mathrm{C}$ with its degradation rate at $0.2 \mathrm{mg} /{ }^{\circ} \mathrm{C}$, and the Gram-Schmidt trace shows far larger degradation intensity at $463^{\circ} \mathrm{C}$, with HEMA characteristic absorptions shown in Figure 13A. These two pieces of evidence are good proof for PHEMA degradation approximately $450^{\circ} \mathrm{C}$.

Moreover, the PHEMA segment in PU networks has a $40^{\circ} \mathrm{C}$ higher average than its starting degradation temperature and maximum degradation temperature when compared to the pure PHEMA reported before $\left(300^{\circ} \mathrm{C}\right.$ or $\left.400^{\circ} \mathrm{C}\right) .^{30-33}$ It can be explained by the cross-link effect from multidouble-bond functionalized PUs and the hydrogen bond interactions between hydroxyl/ester groups of HEMA and carbamate groups of PUs.

To investigate the properties of PU systems that affect the network, PUs synthesized in Table 3 were also used to build up the networks and these networks were compared with each other for their thermal degradation by TGA and DTGA curves, as shown in Figure 15.

Figure 15 clearly shows the effect the PUs bring to the network. First, the degradation temperature of the soft segments in the network increases with the increasing cross-link density of the network. For example, the network based on Run 5 has its first maximum degradation temperature at $262^{\circ} \mathrm{C}$, which is lower than its Run 3 counterpart at $265^{\circ} \mathrm{C}$.
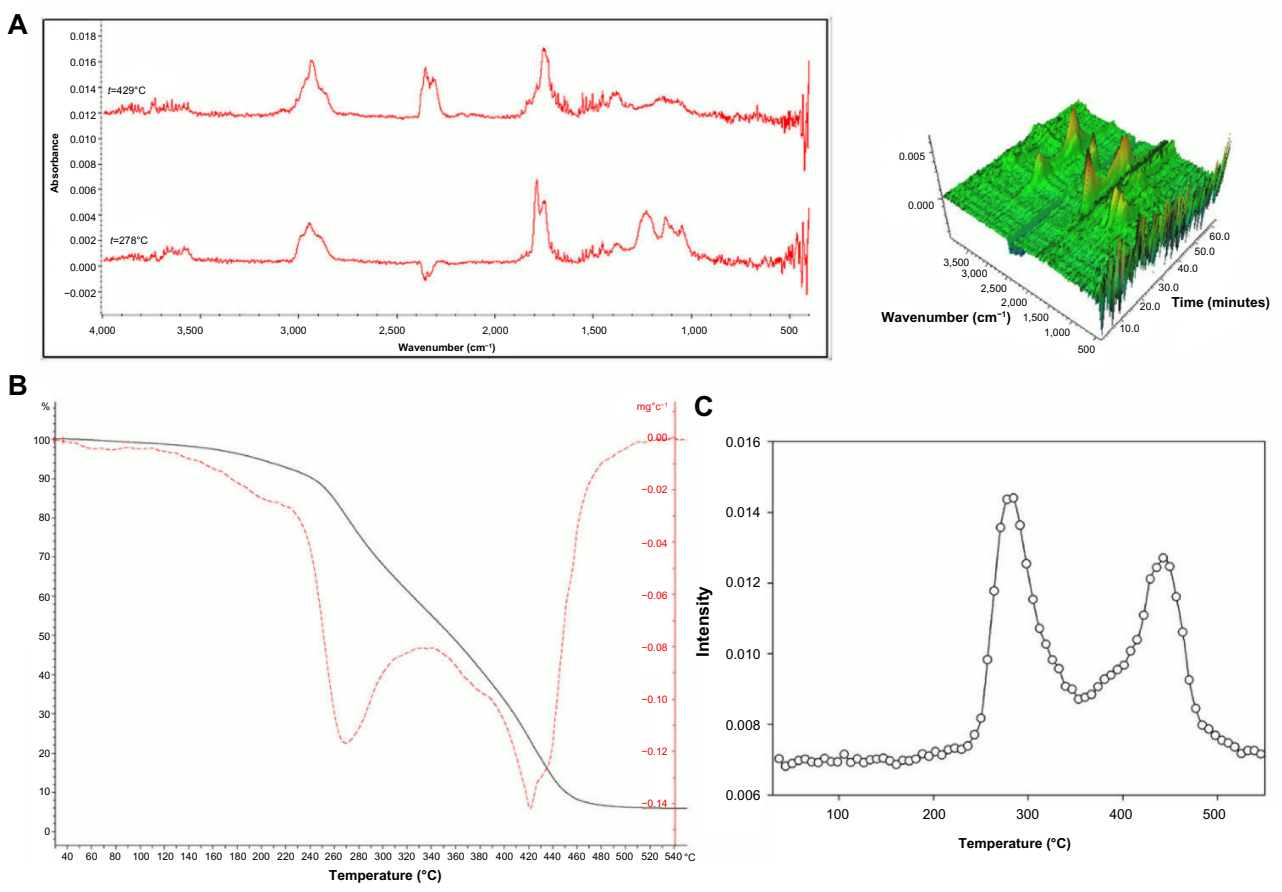

Figure I3 3D FTIR spectra (A), TGA and DTGA (B), and gram-schimdt (C) curves collected during the degradation of networks based on PU Run 3. Note: The FTIR spectra were obtained at the maximum evolution rate for each decomposition step.

Abbreviations: 3D, three-dimensional; FTIR, Fourier transform infrared; TGA, thermogravimetric analysis; DTGA, derivative thermogravimetric analysis; PU, polyurethane. 


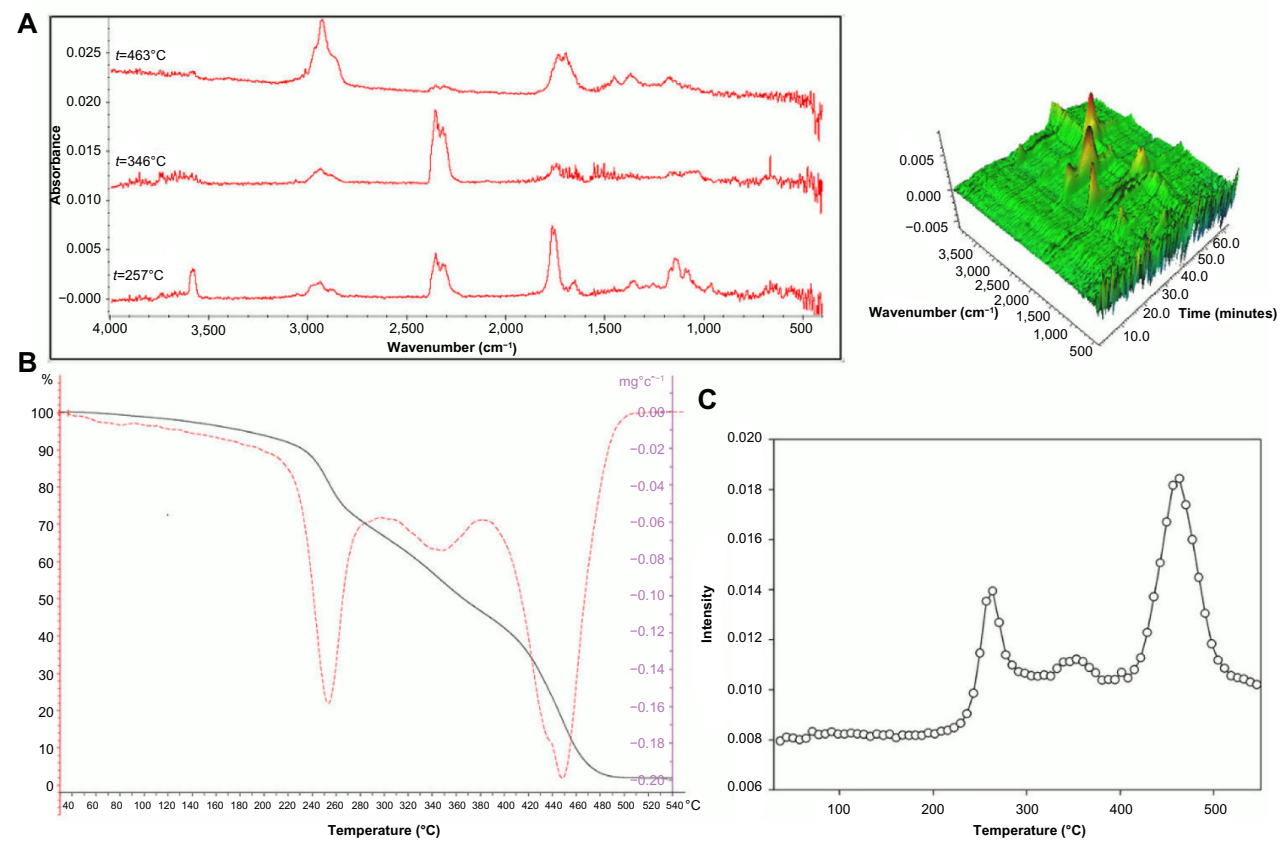

Figure I4 3D FTIR spectra (A), TGA and DTGA (B), and gram-schimdt (C) curves collected during the degradation of a network based on Run 8. Note: The FTIR spectra were obtained at the maximum evolution rate for each decomposition step.

Abbreviations: 3D, three-dimensional; FTIR, Fourier transform infrared; TGA, thermogravimetric analysis; DTGA, derivative thermogravimetric analysis; PU, polyurethane.

This can be explained by the fact that the network based on Run 3 has higher cross-link density than the network based on Run 5.

For the network based on PHB systems, the thermal stability depends on the molar mass of the PHB segment. As shown in Figure 14, Run 11 with higher molar mass PHB segments has a higher degradation temperature than other networks. The cross-linking effect is not obvious for PHB-based networks because the disassociation of carbamate group happened earlier than the degradation of PHB segment, which destroyed the network structure. It can also be seen that networks with PUs having higher $\mathrm{H}_{12} \mathrm{MDI}$ content and longer degradable segments show more stability in thermal degradation, which also corresponds with the conclusion drawn from PU's thermal degradation.

\section{Conclusion}

The poly(ester-urethane)s segmented with prepared PLA and PHB oligomers were synthesized with $\mathrm{H}_{12}$ MDI to strengthen their mechanical properties. The syntheses were performed
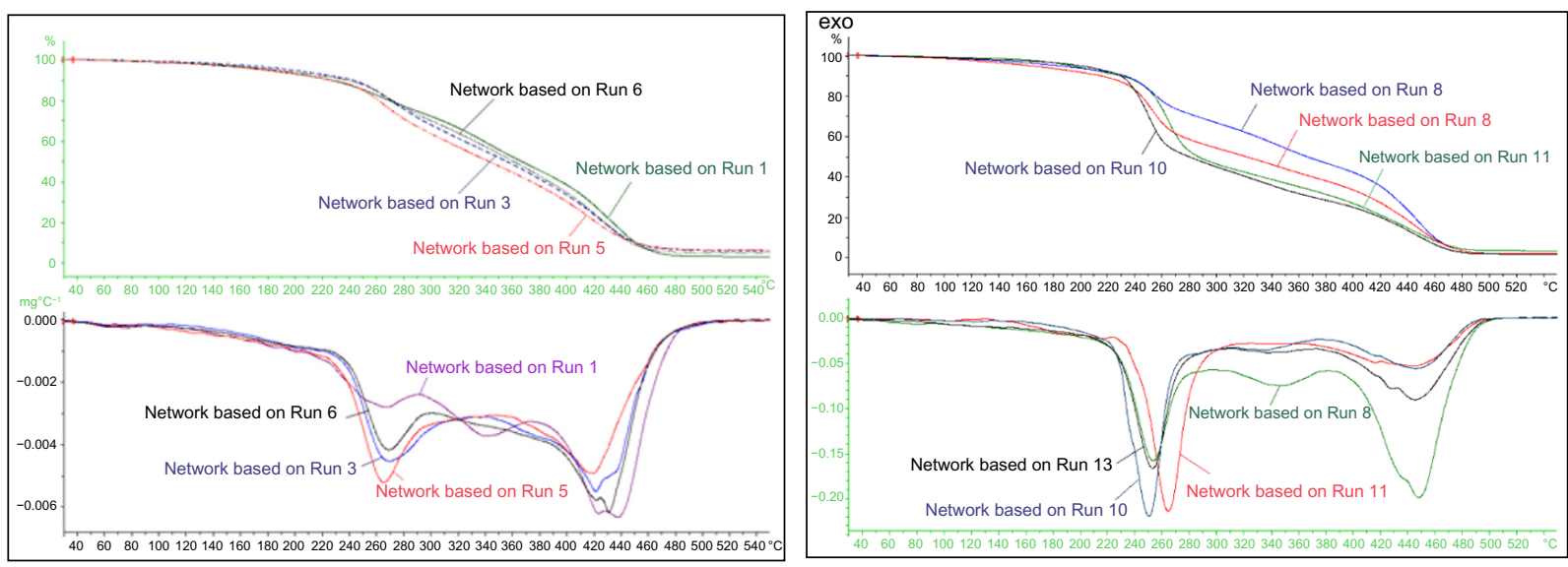

Figure 15 TGA and DTGA curves of polyurethane/PHEMA networks synthesized with different parameters. Notes: Left: PLA-based networks. Right: PHB-based networks.

Abbreviations: TGA, thermogravimetric analysis; DTGA, derivative thermogravimetric analysis; PHEMA, poly(hydroxyethyl methacrylate); PLA, polylactic acid; PHB, polyhydroxybutyrate. 
through two steps and double-bond functionalized PUs were obtained. The structure of these PUs was designed during the syntheses and characterized by ${ }^{1} \mathrm{H}$ NMR, SEC, and DSC tests. These PUs were combined with HEMA to form the networks. TGA-FTIR spectroscopy copolymerization was adapted to characterize the thermal degradation behavior of the dihydroxyl telechelic oligomers, PUs, and the networks. Through this method, designed structures of PUs were also evaluated.

\section{Acknowledgments}

The authors thank the China Scholarship Council (state scholarship fund) for its financial support. This work benefited from the international cooperation between Université JeanMonnet Saint-Etienne (France) and East China University of Science and Technology (China).

\section{Disclosure}

The authors report no conflicts of interest in this work.

\section{References}

1. Kim BK, Paik SH. UV-curable poly(ethylene glycol)-based polyurethane acrylate hydrogel. J Polym Sci A Polym Chem. 1999;37(15): 2703-2709.

2. Lai YC, Baccei LJ. Novel polyurethane hydrogels for biomedical applications. J Appl Polym Sci. 1991;42(12):3173-3179.

3. Zulfiqar M, Quddos A, Zulfiqar S. Polyurethane netwroks based on poly(ethylene oxide). J Appl Polym Sci. 1993;49(12):2055-2063.

4. Zdrahala RJ, Zdrahala IJ. Biomedical applications of polyurethanes. J Biomater Appl. 1999;14(1):67-90.

5. Loh XJ, Sng KBC, Li J. Synthesis and water-swelling of thermoresponsive poly(ester urethane)s containing polycaprolactone, poly(ethylene glycol) and poly(propylene glycol). Biomaterials. 2008; 29(22):3185-3194.

6. Wang WS, Ping P, Chen XS, Jing XB. Biodegradable polyurethane based on random copolymer of L-lactide and $\varepsilon$-caprolactone and its shape-memory property. J Appl Polym Sci. 2007;104(6):4182-4187.

7. Eceiza A, Larranaga M, de la Caba K, et al. Structure-property relationships of thermoplastic polyurethane elastmers based on polycarbonate diols. J Appl Polym Sci. 2008;108(5):3092-3103.

8. Moravek SJ, Storey RF. Reaction kinetics of dicyclohexylmethane4,4'-diisocyanate with 1-and 2-butanol: a model study for polyurethane formation. J Appl Polym Sci. 2008;109(5):3101-3107.

9. Garlotta D. A literature review of poly(lactic acid). J Polym Environ. 2001;9(2):63-84.

10. Michell RM, Muller AJ, Boschetti-de-Fierro A, et al. Novel poly(esterurethane)s based on polylactide: From reactive extrusion to crystallization and thermal properties. Polymer. 2012; 53(25):5657-5665.

11. Cooper TR, Storey RF. Poly(lactic acid) and chain-extended poly(lactic acid)-polyurethane functionalized with pendent carboxylic acid groups. Macromolecules. 2008;41(3):655-662.

12. Gu S, Yang M, Yu T, Ren T, Ren J. Synthesis and characterization of biodegradable lactic acid-based polymers by chain extension. Polym Int. 2008;57(8):982-986.

13. Chen $\mathrm{C}, \mathrm{Yu} \mathrm{CH}$, Cheng $\mathrm{YC}, \mathrm{Yu} \mathrm{PH}$, Cheung MK. Biodegradable nanoparticles of amphiphilic triblock copolymers based on poly(3hydroxybutyrate) and poly(ethylene glycol) as drug carriers. Biomaterials. 2006;27(27):4804-4814.
14. Chen GQ, Wu Q. Polyhydroxyalka as tissue en gineering materials. Biomaterials. 2005;26(33):6565-6578.

15. Hirt TD, Neuenschwander P, Suter UW. Telechelic diols from poly[(R)3hydroxybutyric acid] and poly\{[(R)-3-hydroxybutyric acid]-co[(R)-3-hydroxyvaleric acid]\}. Macromol Chem Phys. 1996;197(5): 1609-1614.

16. Brzeska J, Dacko P, Janeczek H, Kowalczuk M, Janik H, Rutkowska $\mathrm{M}$. The influence of synthetic polyhydroxybutyrate on selected properties of novel polyurethanes for medical applications. part 1. polyurethanes with aromatic diisocyanates in hard segments. Polimery. 2010;55(1):41-46.

17. Liu QY, Cheng ST, Li ZB, Xu KT, Chen GQ. J Biomed Mater Res A. 2009;90A(4):1162-1176.

18. Mallek H, Jegat C, Mignard N, Abid M, Abid S, Taha M. Reversibly crosslinked self-healing PCL-based networks. J Appl Polym Sci. 2013; 129(3):954-964

19. Henry I, Pascault JP, Taha M, Vigier G, Flat JJ. Structure and properties of polyurethane acrylate prepolymers based on hydroxy-terminated polybutadiene. J Appl Polym Sci. 2002;83(2):225-233.

20. Chen J, Pascault JP, Taha M. Synthesis of polyurethane acrylate oligomers based on polybutadiene polyol. J Polym Sci A Polym Chem. 1996;34(14):2889-2907.

21. Coudray S, Pascault J, Taha M. Acrylated polyurethanes by reactive extrusion. Polym Bull. 1994;32(5-6):605-610.

22. Mallek H, Jegat C, Mignard N, Taha M, Abid M, Abid S. One-step synthesis of PCL-urethane networks using a crosslinking/de-crosslinking agent. J Macromol Sci A. 2013;50(7):728-737.

23. Unal S, Ozturk G, Sisson K, Long TE. Poly(caprolactone) containing highly branched segmented poly(esterurethane) via $\mathrm{A}_{2}$ with oligomeric $\mathrm{B}_{3}$ polymerization. J Polym Sci A Polym Chem. 2008;46(18): $6285-6295$.

24. Nakayama Y, Yamaguchi R, Tsutsumi C, Shiono T. Synthesis of poly(ester-urethane)s from hydroxytelechelic polylactide: effect of initiators on their physical and degradation properties. Polym Degrad Stability. 2008;93(1):117-124.

25. Miller DR, Macosko CW. A new derivation of postgel properties of network polymers. Rubber Chem Technol. 1976;49(5): 1219-1231.

26. Vogel C, Siesler HW. Thermal degradation of poly ( $\varepsilon$-caprolactone), poly (L-lactic acid) and their blends with poly (3-hydroxy-butyrate) studied by TGA/FT-IR spectroscopy. Macromol Symposia. 2008;265: 183-194.

27. Nishida H, Ariffin H, Shirai Y, Hassan MA. Determination of multiple thermal degradation mechanisms of poly (3-hydroxybutyrate). Polym Deg Stab. 2008;93(8):1433-1439.

28. Chen C, Fei B, Peng S, Zhuang Y, Dong L, Feng Z. The kinetics of thermal decomposition of poly(3-hydroxybutyrate) and maleated poly(3-hydroxybutyrate). J Appl Polym Sci. 2002;84(9):1789-1796.

29. Cervantes-Uc J, Espinosa J, Cauich-Rodríguez J, et al. TGA/FTIR studies of segmented aliphatic polyuretahnes and their nanocomposites prepared with comercial montmorillonites. Polym Degradat Stability. 2009;94(10):1666-1677.

30. Pielichowski K, Njuguna J. Thermal degradation of polymeric materials. Akron, OH: Smithers Rapra; 2005.

31. Caykara T, Özyürek C, Kantoğlu Ö, Erdoğan B. Thermal behavior of poly(2-hydroxeythyl methacrylate-maleic acid) networks. Polym Degradat Stability. 2003;80(2):339-343.

32. Çaykara T, Güven O. The effect of filler type on thermal degradation of inorganic filled poly(2-hydroxyethyl methacrylate) composites. Polym Degradat Stability. 1998;62(2):267-270.

33. Demirelli K, Coşkun M, Kaya E. A detailed study of degradation of poly(2-hydroxymethyl methacrylate). Polym Degradat Stability. 2001;72(1):75-80.

34. Vargün E, Usanmaz A. Degradation of poly(2-hydroxyethyl methacrylate) obtained by radiation in aqueous solution. J Macromol Sci A Pure Appl Chem. 2010;47(9):882-891. 
Reports in Organic Chemistry

Dovepress

\section{Publish your work in this journal}

Reports in Organic Chemistry is an international, peer-re- Visit http://www.dovepress.com/testimonials.php to read real quotes viewed, open access journal publishing original research, reports, reviews and commentaries on all areas of organic chemistry. The manuscript management system is completely online and includes a very quick and fair peer-review system, which is all easy to use. from published authors.

Submit your manuscript here: http://www.dovepress.com/reports-in-organic-chemistry-journal 